\section{Screening of Watermelon Varieties for Lead Tolerance at the Seedling Stage}

Jehanzeb Khan

Laboratory of Germplasm Innovation and Molecular Breeding, College of Agriculture and Biotechnology, Zhejiang University, Hangzhou, 310058, PR China; Key Laboratory of Horticultural Plant Growth, Development and Quality Improvement, Ministry of Agriculture, Hangzhou 310058, PR China; and Higher Education Department Khyber Pakhtunkhwa, Peshawar, 25000, Pakistan

Yubin Yang

Agriculture, Rural Area and Water Conservancy Bureau of Wenling, Wenling 317500, PR China

\section{Qiang Fu}

School of Continuing Education, Zhejiang University, Hangzhou, 310058, PR China

Weiqiang Shao, Jianke Wang, and Li Shen

Zhejiang Wuwangnong Agricultural Seed Industry Science Research Institute, Hangzhou 310000, PR China

\section{Yan Huai}

Zhejiang Agricultural Technology Extension Center, Hangzhou 310020, PR China

Guy Kateta Malangisha, Abid Ali, and Ahmed Mahmoud

Laboratory of Germplasm Innovation and Molecular Breeding, College of Agriculture and Biotechnology, Zhejiang University, Hangzhou, 310058, PR China

\section{Yi Lin}

Agriculture, Rural Area and Water Conservancy Bureau of Wenling, Wenling 317500, PR China

\section{Yongyuan Ren}

Zhejiang Wuwangnong Agricultural Seed Industry Science Research Institute, Hangzhou 310000, PR China

\section{Jinghua Yang, Zhongyuan Hu, and Mingfang Zhang}

Laboratory of Germplasm Innovation and Molecular Breeding, College of Agriculture and Biotechnology, Zhejiang University, Hangzhou, 310058, PR China; and Key Laboratory of Horticultural Plant Growth, Development and Quality Improvement, Ministry of Agriculture, Hangzhou 310058, PR China

Additional index words. accumulation, hydroponic screening, lead tolerance, translocation, watermelon

Abstract. Watermelon (Citrullus lanatus) is an important horticultural crop that is sensitive to heavy metals such as lead $(\mathrm{Pb})$ in polluted water or soil. However, there are no available data regarding $\mathrm{Pb}$ tolerance phenotyping in watermelon. Watermelon seedlings were exposed to various $\mathrm{Pb}$ doses $\left(0,20,40,60,80 \mu \mathrm{M} \cdot \mathrm{L}^{-1} \mathrm{~Pb}\right)$ for 14 days, after which $20 \mu \mathrm{M} \mathrm{Pb}$ was identified as the optimal treatment for lead tolerance analysis in watermelon because it caused significant symptoms (leaf chlorosis, stubby and yellow roots) but little damage to seedlings. Subsequently, the $\mathrm{Pb}$ responses were analyzed in eight watermelon varieties (V1-V8), and membership function analysis was used to determine a single $\mathrm{Pb}$ tolerance index. Of the eight watermelon varieties, V4 and V7 were ranked the most Pb tolerant; V1, V2, V5, and V6 were moderately $\mathrm{Pb}$ tolerant; and $\mathrm{V} 3$ and $V 8$ were the most $\mathrm{Pb}$-sensitive varieties. Compared with most Pb-sensitive varieties (V3 and V8), the most Pb-tolerant varieties (V4 and V7) maintained high antioxidant activity, and had lower malondialdehyde (MDA) and total soluble protein (TSP) contents. In addition, carotenoid and chlorophyll (both a and b) contents were stimulated and inhibited, respectively, in leaves of high-Pb translocation varieties (V4 and V8). Principal component analysis (PCA) revealed relative root length as an indicator of $\mathrm{Pb}$ tolerance because it correlated significantly with shoot growth. These results provide useful insight into the mechanism of $\mathrm{Pb}$ tolerance in cucurbit crops, as well as information regarding the breeding of watermelon with enhanced tolerance to this heavy metal (Pb).
Lead (plumbum, $\mathrm{Pb}$ ) is a nonessential element for plants and one of the hazardous heavy-metal pollutants in the environment. The most important sources of $\mathrm{Pb}$ contamination are mining, pesticides, fossil fuels, sewage sludge, and fertilizers (Huang et al., 2017). Toxicity of $\mathrm{Pb}$ in plant tissues can be recognized by the alterations in biochemical and physiological processes (Maodzeka et al., 2017) associated with depression in plant growth (Zhou et al., 2014), and reduction in yield and quality (Ashraf et al., 2017; Rao et al., 2018; Zhong et al., 2017). However, the extent of these effects varies and depends on the $\mathrm{Pb}$ concentration and the duration of exposure (Nas and Ali, 2018; Pidatala et al., 2016), the intensity of plant stress, the stage of plant development, and the particular organs or organelles (Sun and Luo, 2018). Plants have developed various methods for responding to toxic effects of $\mathrm{Pb}$ exposure, such as selective uptake, binding to root surface and cell wall, and induction of antioxidants (Khan et al., 2014; Zhong et al., 2017).

$\mathrm{Pb}$ availability to plants depends on many factors, such as soil texture, organic matter content, $\mathrm{pH}$, and the forms and concentration of $\mathrm{Pb}$ in the soil profile (Cândido et al., 2020; Chen et al., 2015; Radziemska et al., 2020). Plant roots have the ability to absorb significant amounts of $\mathrm{Pb}$ because of the thin cell walls of the root apices (Seregin et al., 2004) that greatly restrict its translocation to aboveground parts (Almasi et al., 2019). However, a greater concentration of $\mathrm{Pb}$ damage plasmalemma and a greater amount of it enter the cell (Jiang et al., 2018; Seregin et al., 2004). The low translocation of $\mathrm{Pb}$ from roots to shoots is a result of the accumulation of $\mathrm{Pb}$ in the intercellular spaces as insoluble phosphates, oxalates, and chlorates and, its precipitation as $\mathrm{Pb}$ carbonate deposited in the cell wall. Similarly, casparian strips of the endodermis restrict $\mathrm{Pb}$ transport into the central cylinder tissue, resulting in lower translocation to aboveground organs of the plants (Ashraf et al., 2020; Zhou et al., 2018). Despite the ability of roots to restrict $\mathrm{Pb}$ upward translocation, there are hyperaccumulators plants such as Chenopodium murale L. (Sidhu et al., 2018) and Emilia sonchifolia L. (Zhou et al., 2015) that accumulate greater $\mathrm{Pb}$ amounts in shoots.

$\mathrm{Pb}$ tolerance varies among different plant species (Cândido et al., 2020) and among varieties within the same species (Wang et al., 2014). Similarly, $\mathrm{Pb}$ uptake and accumulation varies among genotypes and cultivars of the same species (Ashraf et al., 2020; Liu et al., 2009, 2013; Maodzeka et al., 2017). These variations in $\mathrm{Pb}$ tolerance, uptake, and accumulation are a result of the differences in strategies used by plants to handle $\mathrm{Pb}$ stress, such as $\mathrm{Pb}$ uptake, accumulation, and translocation potential (Ashraf et al., 2020; Ho et al., 2008; Liu et al., 2013); restriction of $\mathrm{Pb}$ to the cell wall (Qiao et al., 2015); sequestration of $\mathrm{Pb}$ in vacuoles (He et al., 2015; Morel et al., 2009); synthesis and secretion of organic acids, which in turn precipitate $\mathrm{Pb}$ (Yang et al., 2000); and antioxidant enzyme activities (Mahdavian et al., 2016). In general, seed germination and 
early stages of seedling growth are more sensitive to $\mathrm{Pb}$ stress and are widely used in the assessment of $\mathrm{Pb}$ toxicity (González-Valdez et al., 2015; Kong et al., 2014). Differences in morphological, physiological, and biochemical responses of plants to $\mathrm{Pb}$ stress have been used to evaluate $\mathrm{Pb}$ tolerance and sensitivity (Mahdavian et al., 2016; Maodzeka et al., 2017). Similarly, growth parameters such as biomass, and root and shoot length have been used as indicators of heavy-metal toxicity in plants (Alaboudi et al., 2018; Liu et al., 2020).

China is the world leading producer and consumer of watermelon, one of the most important crops worldwide (Sheng et al., 2012). $\mathrm{Pb}$-contaminated agricultural soils is becoming a serious problem in watermelon production recently, especially in the main producing areas of the southeast provinces (Ashraf et al., 2020; Ma et al., 2015; Wei and Yang, 2010). Effects of $\mathrm{Pb}$ on watermelon growth is prominent but not fully recognized (Akıncı and Çalışkan, 2010). However, it is wellknown that watermelon growth may be affected seriously by the concentration of $\mathrm{Pb}$ in soil. Toxicity of $\mathrm{Pb}$ may result in symptoms such as wilting, slow growth rate, reduced fruit size, and more. We identified $\mathrm{Pb}$-tolerant and -sensitive watermelon varieties, and contribute our results to the $\mathrm{Pb}$-tolerant breeding of watermelon that produce more healthy fruit under $\mathrm{Pb}$ pollution. Therefore, we addressed for the first time $\mathrm{Pb}$ stress adaptation in watermelon, screened eight varieties with respect to $\mathrm{Pb}$ stress, and classified their tolerance based on morphological and biochemical changes. The description and clarification of $\mathrm{Pb}$ stress phenotyping and adaptation in watermelon could provide clues to understanding and improving $\mathrm{Pb}$ tolerance in other crop plants.

Received for publication 9 Jan. 2020. Accepted for publication 26 Mar. 2020.

Published online 6 May 2020.

This work was supported by China Agriculture Research System (CARS-25-17), the National Key Research and Development Plan of China (2018YFD0201300), the National Natural Science Foundation of China (31501782, 31672175, and 31372077), the Fundamental Research Funds for the Central Universities (2017QNA6016), Natural Science Foundation of Zhejiang Province (LQ16C150002), and the Key Science and Technology Program of Zhejiang Province (2016C02051-4-1).

We thank engineer Afed Ullah Khan, School of Municipal and Environmental Engineering, Harbin Institute of Technology, China, for performing principal component analysis of the results. Z.H., J.Y., and M.Z. conceived and designed the study; J.K. conducted all experiments and wrote the manuscript; Z.H. and J.K. participated in results analysis; A.A., A.M., and G.K.M. helped perform parts of experiments; and all authors reviewed the manuscript.

Z.H. is the corresponding author. E-mail: huzhongyuan@zju.edu.cn.

This is an open access article distributed under the CC BY-NC-ND license (https://creativecommons.org/ licenses/by-nc-nd/4.0/).

\section{Materials and Methods}

Plant material and hydroponic culture. Eight varieties of watermelon (Citrullus lanatus)_JBT, KB948, LF, NBT, XF1, XF, ZM5, and ZJ (represented as V1-V8)-were used in this study. Watermelon seeds were dipped in water at $55{ }^{\circ} \mathrm{C}$ for $15 \mathrm{~min}$ and then stored at room temperature for $4 \mathrm{~h}$. Next, they were sterilized by $70 \%$ ethanol for $30 \mathrm{~s}$ and rinsed in sterile distilled water five times. The seeds were germinated at $30{ }^{\circ} \mathrm{C}$ for $24 \mathrm{~h}$ in darkness. Seedlings were supplied with half-strength Hoagland's solution in a growth room under control conditions $\left(16 \mathrm{~h} / 26{ }^{\circ} \mathrm{C}\right.$ day and $8 \mathrm{~h} / 23{ }^{\circ} \mathrm{C}$ night, at a light intensity of $250-300 \mu \mathrm{M}$ photon $/ \mathrm{m}^{2} / \mathrm{s}$, and a relative humidity of $\approx 55 \%$ to $60 \%$ ). After $8 \mathrm{~d}$, seedlings with uniform size were selected and wrapped in foam, and transferred into plate holes on plastic pots (five seedling per pot) containing half-strength Hoagland nutrient solution (Arnon and Hoagland, 1940), in which the monopotassium phosphate concentration was adjusted to $0.04 \mu \mathrm{M}$ to avoid possible $\mathrm{Pb}$ precipitation (Zhivotovsky et al., 2010) (Supplemental Table 1). The nutrient solutions were continuously aerated and renewed every $2 \mathrm{~d}$.

Dose optimization. To determine the optimal $\mathrm{Pb}$ concentration that causes minimal damage to watermelon seedlings, the most popular variety-ZJ - was selected. Fourteenday-old seedlings were exposed for 2 weeks (this during was found to be nonlethal, but resulted in significant toxicity symptoms in all preexperiments) to $\mathrm{Pb}$ stress $(0,40,60,80$ $\left.\mu \mathrm{M} \cdot \mathrm{L}^{-1} \mathrm{~Pb}\right) . \mathrm{C} 1$ is general control while modified control $\mathrm{C} 2$ and the treatment solutions containing $0.04 \mu \mathrm{M}$ phosphorus (P) to evade possible $\mathrm{Pb}$ precipitation with $\mathrm{P}$ in the nutrient solution (Zhivotovsky et al., 2010).

$\mathrm{Pb}$ tolerance screening in watermelon. The root length and shoot height of each seedling were measured before and after treatment. Fresh weight of roots and shoots were weighted immediately after harvest, and were then placed in a preheated oven at $80^{\circ} \mathrm{C}$ for $2 \mathrm{~d}$, after which dry weight was determined using an electronic balance. The leaf area of the first fully expanded leaf was calculated using Image $\mathbf{J}$ software (Image $\mathbf{J}$ version ij152-win-java8; National Institutes of Health, Bethesda, MD). Data were collected as the mean of five similar seedlings, and relative growth was calculated as the ratio of $\mathrm{Pb}$ treatment to the control.

The $\mathrm{Pb}$ tolerance index of the watermelon varieties was calculated using the membership function by integrating the relative root length (RRL), relative shoot height (RSH), relative root fresh weight (RRFW), relative root dry weight (RRDW), relative shoot fresh weight (RSFW), relative shoot dry weight (RSDW), and relative leaf area (RLA). The $\mathrm{Pb}$ tolerance index was computed using Eq. [1],

$$
X_{u}=\frac{X-X_{\min }}{X_{\max }-X_{\min }}
$$

where $X_{u}$ is the subordinate value representing RRL, RSH, RRFW, RRDW, RSFW,
RSDW, and RLA. $X$ is the measured value of the growth parameter; $X_{\max }$ and $X_{\min }$ are the maximum and minimum value of the growth parameter.

$\mathrm{Pb}$ content analysis and translocation factor. For elemental analysis, the two most $\mathrm{Pb}$-tolerant (V4 and V7), two more $\mathrm{Pb}$ tolerant (V2 and V6), and two most $\mathrm{Pb}$ sensitive (V3 and V8) varieties were selected and grown in 0 and $20 \mu \mathrm{M} \cdot \mathrm{L}^{-1} \mathrm{~Pb}$ for 2 weeks. Treated plants were then harvested and washed with distilled water to remove impurities, and blotted dry. Roots and shoots were dried in an oven at $80{ }^{\circ} \mathrm{C}$ for $48 \mathrm{~h}$, and were then ground into powder. Root and shoot samples $(0.1 \mathrm{~g})$ were treated sequentially in $6 \mathrm{~mL}$ concentrated nitric acid and $200 \mu \mathrm{L}$ hydrogen peroxide $\left(\mathrm{H}_{2} \mathrm{O}_{2} ; 30 \%\right)$, and the mixture was heated using a microwave reaction system (Multiwave 3000 Anlou Paor). Thereafter, samples were digested at $160{ }^{\circ} \mathrm{C}$ for $4 \mathrm{~h}$, and then diluted with double-distilled water up to $30 \mathrm{~mL}$. $\mathrm{Pb}$ content was eventually evaluated via inductively coupled plasma optical emission spectroscopy from a diluted solution (ICP-OES optima 8000 DV; Perkin Elmer).

The translocation factor $(T F)$ is the ability of a plant to translocate the accumulated $\mathrm{Pb}$ from its roots to aboveground parts. It can be calculated as shown in Eq. [2],

$$
T F=\frac{\mathrm{Pb}_{(\text {aboveground parts })}}{\mathrm{Pb}_{(\text {roots })}}
$$

where $\mathrm{Pb}$ (aboveground parts) is the concentration of $\mathrm{Pb}$ in aerial tissues, and $\mathrm{Pb}$ (roots) is the concentration of $\mathrm{Pb}$ in the roots.

Biochemical assays. The lipid peroxide levels were determined by measuring the MDA content from the thiobarbituric acid reaction as described by El-Moshaty et al. (1993) Samples $(\approx 0.5 \mathrm{~g})$ were homogenized in $1.5 \mathrm{~mL} \mathrm{5 \%}$ trichloroacetic acid (w/v) and centrifuged at $3000 \mathrm{rpm}$ for $10 \mathrm{~min}$, and then the supernatant was diluted to $10 \mathrm{~mL}$. Two milliliters of the diluted extract was mixed with $2 \mathrm{~mL} 0.67 \%$ 2-thiobarbituric acid and the mixture was incubated in boiling water $\left(100^{\circ} \mathrm{C}\right)$ for $20 \mathrm{~min}$, cooled on ice, and then centrifuged at $3000 \mathrm{rpm}$ for $10 \mathrm{~min}$. The absorbance was measured at $532 \mathrm{~nm}$

The measurement of TSP content was done by the homogenization of a $0.5-\mathrm{g}$ (roots and leaves) sample with pestle and mortar (Bradford, 1976). The homogenate was centrifuged for $10 \mathrm{~min}$ at $12,000 \mathrm{~g}_{\mathrm{n}}$, and an aliquot of the extract was used to determine protein content, using bovine serum albumin as the standard.

Total soluble sugar (TSS) was estimated using the method of Yemm and Willis (1954) with a 0.1 -g plant sample (roots and leaves). The homogenized sample was extracted twice in $80 \%$ ethanol and evaporated to dryness in a test tube in a hot water bath at $100{ }^{\circ} \mathrm{C}$. Absorbance of this solution was 
measured at $620 \mathrm{~nm}$ against the reagent blank using a spectrophotometer (UV-VIS 2550; Schimadzu, Kyoto, Japan).

A 0.5 -g fresh leaf sample was taken and homogenized (using a pestle and mortar) and, along with $10 \mathrm{~mL} 80 \%$ acetone, centrifuged at $10,000 \mathrm{rpm}$ for $15 \mathrm{~min}$ at $4{ }^{\circ} \mathrm{C}$. The solution was analyzed for chlorophyll a, chlorophyll b, and carotenoid content using a spectrophotometer (UV-VIS 2550; Schimadzu) according to Lichtenthaler and Wellburn (1983).

For the enzyme activity assay, 0.5 -g plant samples (roots and leaves) were homogenized in $8 \mathrm{~mL} 50 \mathrm{~mm}$ potassium phosphate buffer (pH 7.8) using a chilled mortar and pestle in an ice bath. The homogenate was centrifuged at $10,000 g_{\mathrm{n}}$ at $4{ }^{\circ} \mathrm{C}$ for $20 \mathrm{~min}$ and the supernatant was used to determine the enzymatic activities of superoxide dismutase (SOD), peroxidase (POD), catalase (CAT), and ascorbate peroxidase (APX), as described by Mahdavian et al. (2016). All spectrophotometric analyses were conducted using a Shimadzu UV-2550 spectrophotometer.

Determination of $\mathrm{Pb}$ tolerance indicator parameter and statistical analysis. PCA was conducted on the relative growth parameters (RRL, RSH, RRFW, RRDW, RSFW, RSDW, and RLA) to determine the major parameter causing variability among the components. The extracted components (PC1 and PC2) were represented in a scatterplot (not shown) to analyze associations among relative growth parameters based on their loading factor values. The experiment was conducted in a completely randomized design with three replicates, and three pots were used for each variety. The data were analyzed using SPSS software (SPSS Version 16.0; SPSS Inc., Chicago, IL). Differences among groups were assessed by one-way analysis of variance followed by $t$ tests. Values in the text are mean \pm SD (SD of three replicate samples). Differences with $P<$ 0.05 were considered to be statistically significant.

\section{Results}

Effect of different $\mathrm{Pb}$ concentrations on watermelon seedling growth. $\mathrm{Pb}$ concentrations ranging from 0 to $80 \mu \mathrm{M} \cdot \mathrm{L}^{-1}$ were used to identify the optimum $\mathrm{Pb}$ concentration, which can cause visible symptom and minimum growth reduction in watermelon seedlings. The shoot height, shoot fresh weight, shoot dry weight, root length, root fresh weight, and root dry weight were measured after being treated for 2 weeks with $\mathrm{Pb}$ at a dose of $0,20,40,60$, or 80 $\mu \mathrm{M} \cdot \mathrm{L}^{-1} \mathrm{~Pb}$ (Fig. 1). Significant reductions in shoot dry weight and root fresh weight were observed in C2 compared with C1 ( $19.9 \%$ and $20.97 \%$, respectively), whereas other growth parameters were found to be nonsignificant and no significant differences between $\mathrm{C} 1$ and $\mathrm{C} 2$ were identified (Fig. 2C and F). In general, $\mathrm{Pb}$ treatment inhibited most of the growth parameters

A

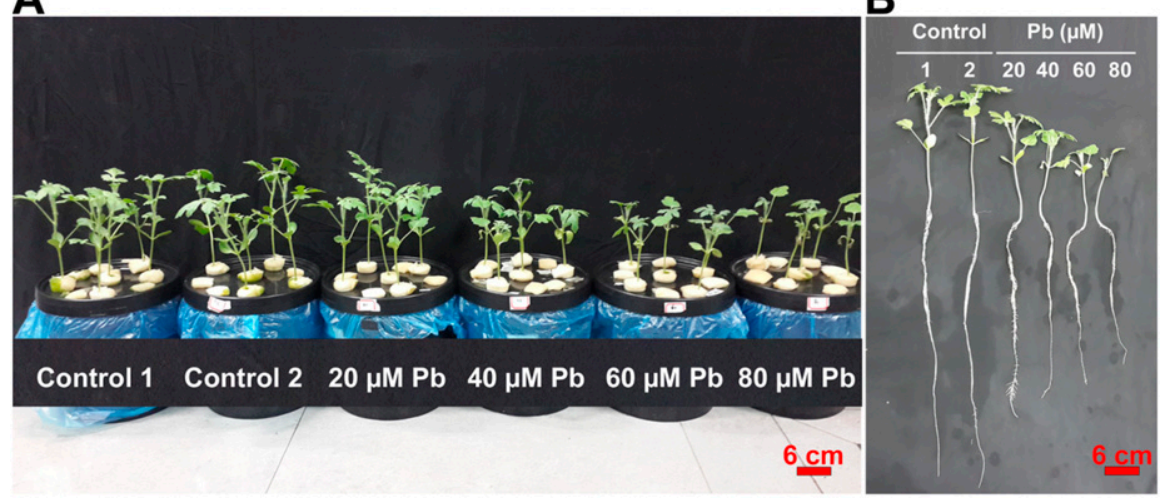

Fig. 1. Growth comparison of watermelon variety $\mathrm{ZJ}$ exposed to $20 \mu \mathrm{M} \mathrm{Pb}$ for $14 \mathrm{~d}$ in Hoagland's nutrient solution. (A) Comparison showing growth of $\mathrm{ZJ}$ in control (C1 and C2) and in 20-, 40-, 60-, and $80-\mu \mathrm{M} \mathrm{Pb}$ treatments (from left to right). (B) Whole seedling in control (C1 and C2) and in 20-, 40-, 60-. and $80-\mu \mathrm{M} \mathrm{Pb}$ treatments (from left to right). $\mathrm{C} 1$ is the general control whereas $\mathrm{C} 2$ is the modified control (containing $0.04 \mu \mathrm{M}$ P to avoid $\mathrm{Pb}$ precipitation with $\mathrm{P}$ in nutrient solution).

(shoot height, shoot fresh weight, shoot dry weight, root length, root fresh weight) in a dose-dependent manner (Fig. 2A-D and F), with the exception of the $20-\mu \mathrm{M} \cdot \mathrm{L}^{-1} \mathrm{~Pb}$ treatment, which increased root dry weight by $10.39 \%$ compared with control groups, suggesting that a low concentration of $\mathrm{Pb}$ may induce biomass accumulation in watermelon root (Fig. 2E). The greater $\mathrm{Pb}$ concentration $\left(80 \mu \mathrm{M} \cdot \mathrm{L}^{-1}\right)$ inhibited shoot height, shoot fresh weight, shoot dry weight, root length, root fresh weight, and root dry weight by $34.61 \%, 63.94 \%$, $65.58 \%, 30.55 \%, 70.44 \%$, and $66.66 \%$, respectively. Thus, treatment of $20 \mu \mathrm{M} \mathrm{Pb}$ and a 2-week exposure was selected as the optimum condition for inducing $\mathrm{Pb}$ toxicity and studying $\mathrm{Pb}$ tolerance in watermelon, because plants started to exhibit significant differences in each parameter under this condition.

$\mathrm{Pb}$ tolerance index. To identify $\mathrm{Pb}$ tolerant and -sensitive genotypes, eight watermelon varieties were used, and their relative growth parameters were measured $14 \mathrm{~d}$ after treatment with or without $20 \mu \mathrm{M} \cdot \mathrm{L}^{-1} \mathrm{~Pb}$ application. $\mathrm{Pb}$ tolerance based on the relative root length revealed that the majority of watermelon varieties were $\mathrm{Pb}$ sensitive and showed more than $50 \%$ root length inhibition except for V7 (26.33\%), V1 (35.51\%), and V5 (40.03\%) (Fig. 3A). Pb tolerance based on the relative root fresh weight revealed that, in V4, V5, and V7, it was enhanced by $13.28 \%$, $37.83 \%$, and $38.07 \%$ (Fig. 3C). Pb tolerance based on the relative root dry weight revealed that it was decreased in V3 and V1 by $18.08 \%$ and $35.58 \%$, respectively, and enhanced in other varieties (ranging from $14.2 \%$ to $239.6 \%$ ) (Fig. 3D). Shoot height was not very sensitive to $\mathrm{Pb}$ stress, as severe inhibition was observed in $\mathrm{V} 8$ only $(40.62 \%)$, whereas stimulated shoot height was found in V5 $(4.79 \%)$ and V4 (13.24\%) (Fig. 3B). However, shoot fresh weight and dry weight data were did not always correlate with the pattern of shoot height. $\mathrm{Pb}$ increased relative shoot fresh weight in V7 only (16.23\%), whereas an inhibitory effect was found in other varieties (ranging from $4.73 \%$ in V4 to $40.43 \%$ in V3) (Fig. 3E). $\mathrm{Pb}$ stimulated relative shoot dry weight in $\mathrm{V} 4, \mathrm{~V} 1$, and $\mathrm{V} 7$, whereas inhibition in other varieties occurred, showing other possible $\mathrm{Pb}$-tolerance patterns (Fig. 3F). Similarly, leaf area was stimulated by $\mathrm{Pb}$ treatment in V7, V2, V4, and V6, and decreased in other varieties (Fig. 3G).

To identify the most $\mathrm{Pb}$-tolerant and -sensitive watermelon varieties for further investigation, different relative growth indexes were integrated to get a single $\mathrm{Pb}$ tolerance index by membership function analysis (MFA) (Fig. 4). The varieties were grouped with respect to the tolerance index, and V4 and V7 were designated as the most tolerant varieties according to this grading criterion of mean value $\bar{X}_{u} \geq 0.8$. Four varieties (V1, V2, V5, and V6) with an $\bar{X}_{u}$ value around 0.4 to 0.6 were classified as moderate varieties. V3 and V8 $\left(\bar{X}_{u} \leq 0.2\right)$ were found to be the most sensitive varieties (Fig. 4). MFA identified the most Pb-tolerant (V4 andV7) and most $\mathrm{Pb}$-sensitive (V3 and V8) varieties, although it was difficult from the relative growth indexes to find the most $\mathrm{Pb}$-tolerant and -sensitive varieties because of variations in trends (Fig. 3).

$\mathrm{Pb}$ content and its translocation in watermelon tissue. For the comparison of variations in $\mathrm{Pb}$ concentration and translocation factor values, the two most $\mathrm{Pb}$-tolerant and two most $\mathrm{Pb}$-sensitive watermelon varieties were examined. $\mathrm{Pb}$ concentration, accumulation, and translocation ratio varied among the watermelon varieties (Fig. 5). $\mathrm{Pb}$ concentration in roots was much greater than that in shoots for each variety. Interestingly, the greatest $\mathrm{Pb}$ concentration in both roots and shoots was found in V4 (Fig. 5A and B), which show a significantly lower $\mathrm{Pb}$ concentration in leaves (Fig. 5C). V8, one of the most sensitive watermelon varieties, and showed 
A

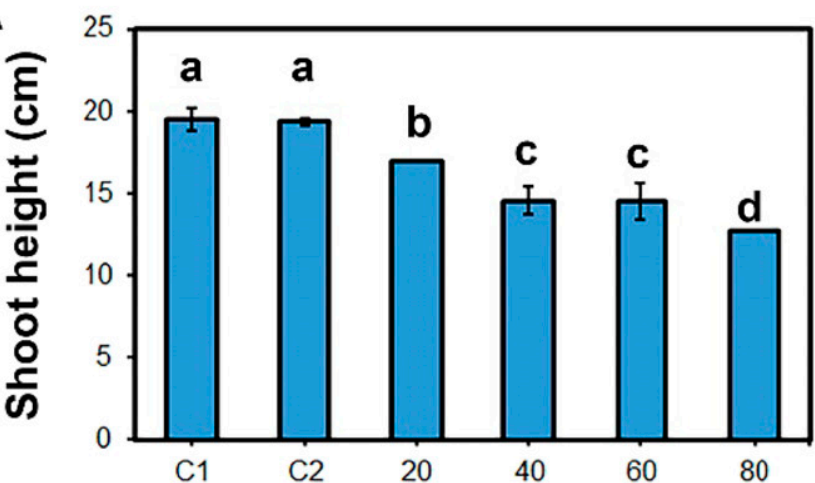

C

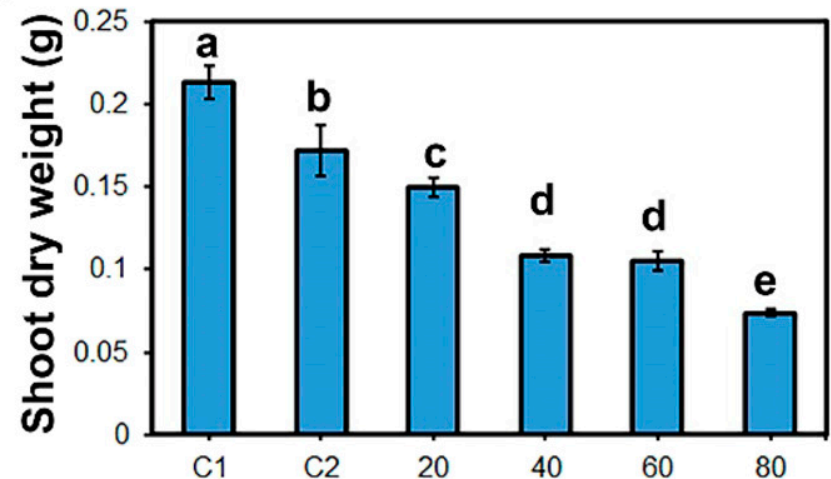

E

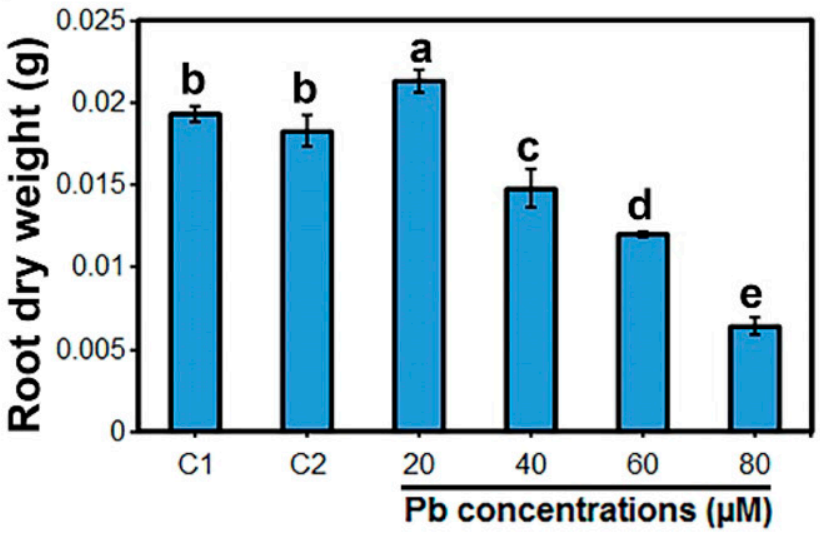

B

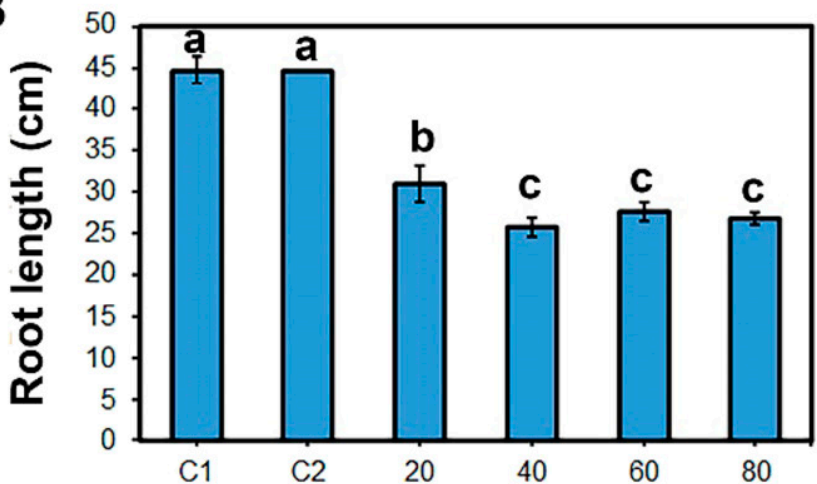

D

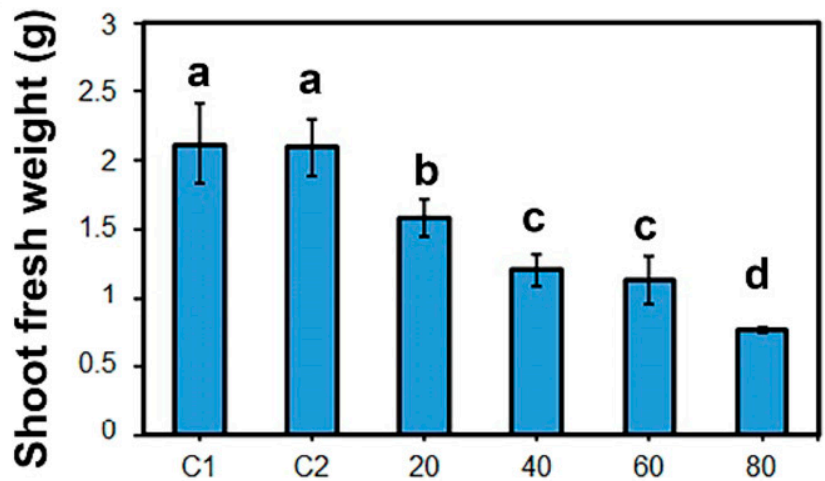

$F$

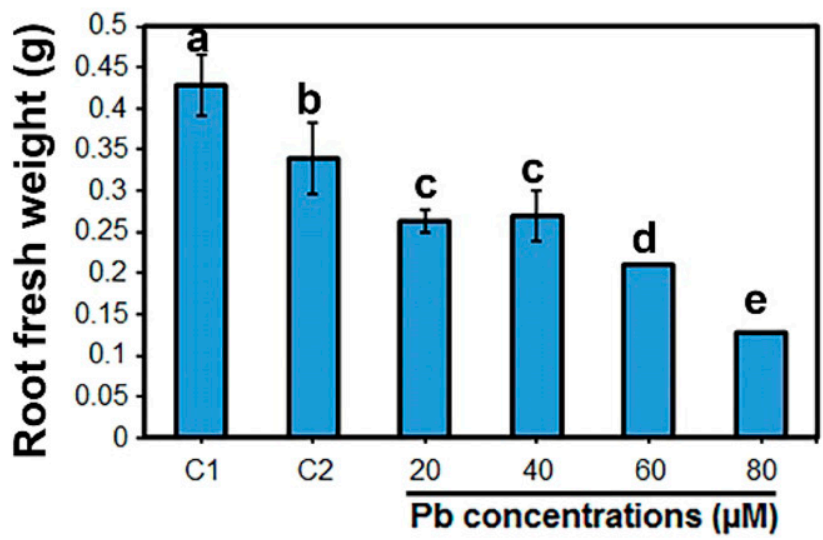

Fig. 2. Average growth responses of roots and shoots of watermelon variety ZJ after $14 \mathrm{~d}$ of exposure to different concentrations of Pb in Hoagland's nutrient solution. (A) Shoot height. (B) Root length. (C) Shoot dry weight. (D) Shoot fresh weight. (E) Root dry weight. (F) Root fresh weight.

Values given are mean $\pm \mathrm{SD}(\mathrm{n}=3)$. Values with different letters are significantly different $(P \leq 0.05)$ among treatments.

a much greater translocation ability than the other varieties (Fig. 5D). These results suggest that $\mathrm{Pb}$ tolerance and translocation are different traits.

Influence of $\mathrm{Pb}$ toxicity on the contents of MDA, TSP, TSS, and photosynthetic pigments. MDA content assay was used to assess the oxidative lipid damage in watermelon varieties under $\mathrm{Pb}$ stress. A significant increase in MDA was observed in both leaves and root tissues of the $\mathrm{Pb}$-sensitive varieties, whereas it was slightly induced in tolerant watermelon varieties (Fig. 6A and $\mathrm{B}$ ). $\mathrm{Pb}$ toxicity led to an opposite variation in TSP content in leaves of tolerant and sensitive varieties, even when it induced TSP accumulation in roots of both watermelon types (Figs. 6C and 7D). TSS content was significantly increased in all varieties (Fig. 6E and $\mathrm{F}$ ). Under $\mathrm{Pb}$ stress, chlorophyll a content increased in V3 and V7, whereas it declined in V8 and V4 (Fig. 7A). A similar pattern was also observed in chlorophyll b content (Fig. 7B). Contrary to chlorophyll $\mathrm{a}$ and $\mathrm{b}$ contents, carotenoid content increased in V4 $(557 \%)$ and V8 $(125 \%)$, but decreased by $49 \%$ in $\mathrm{V} 3$ (Fig. 7C). These results demonstrate that more $\mathrm{Pb}$ accumulation in the shoots of V4 and V8 likely disturbed the photosynthetic machinery.

Antioxidative response of watermelon varieties to $\mathrm{Pb}$ stress. $\mathrm{Pb}$ treatment affected antioxidant activities differently in the
$\mathrm{Pb}$-tolerant and -sensitive watermelon varieties in terms of $\mathrm{SOD}, \mathrm{POD}, \mathrm{CAT}$, and APX (Fig. 8). A significant increase in SOD was found in both leaves and roots of tolerant watermelons (V4 and V7; Fig. 8A and $\mathrm{B})$, and slightly increased or decreased SOD was observed in less-sensitive watermelon (V8 and V3; Fig. 8A and B). Similarly, SOD activity increased in roots by $81 \%, 46 \%$, and $11 \%$ in V4, V7, and V8, respectively, with a slight decrease of $0.9 \%$ in V3 (Fig. $8 \mathrm{~B}$ ). POD activity declined by $18.9 \%$ in $\mathrm{V} 3$ leaves, but increased enormously in the other varieties by $374 \%, 163 \%$, and $43 \%$ in V7, V4, and V8 (Fig. 8C). POD activity increased in roots of $\mathrm{V} 7, \mathrm{~V} 4, \mathrm{~V} 8$, and $\mathrm{V} 3$ by $181 \%, 87 \%, 58 \%$, and $45 \%$ respectively 
A

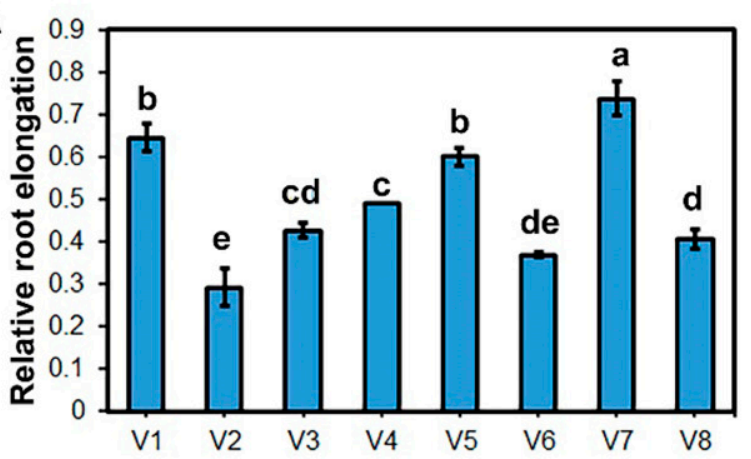

C

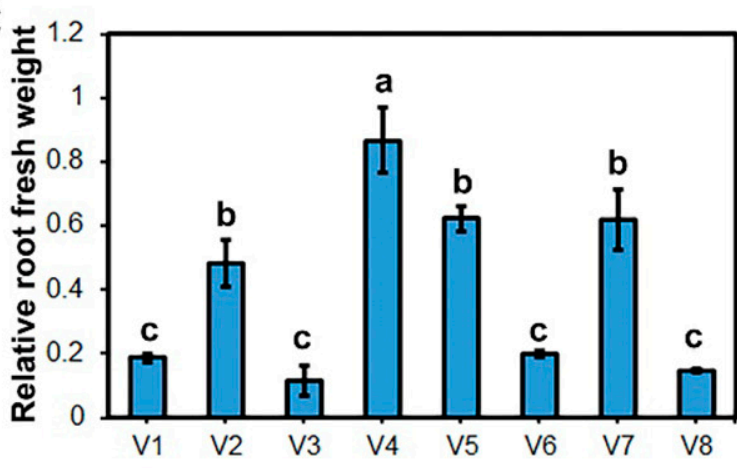

E
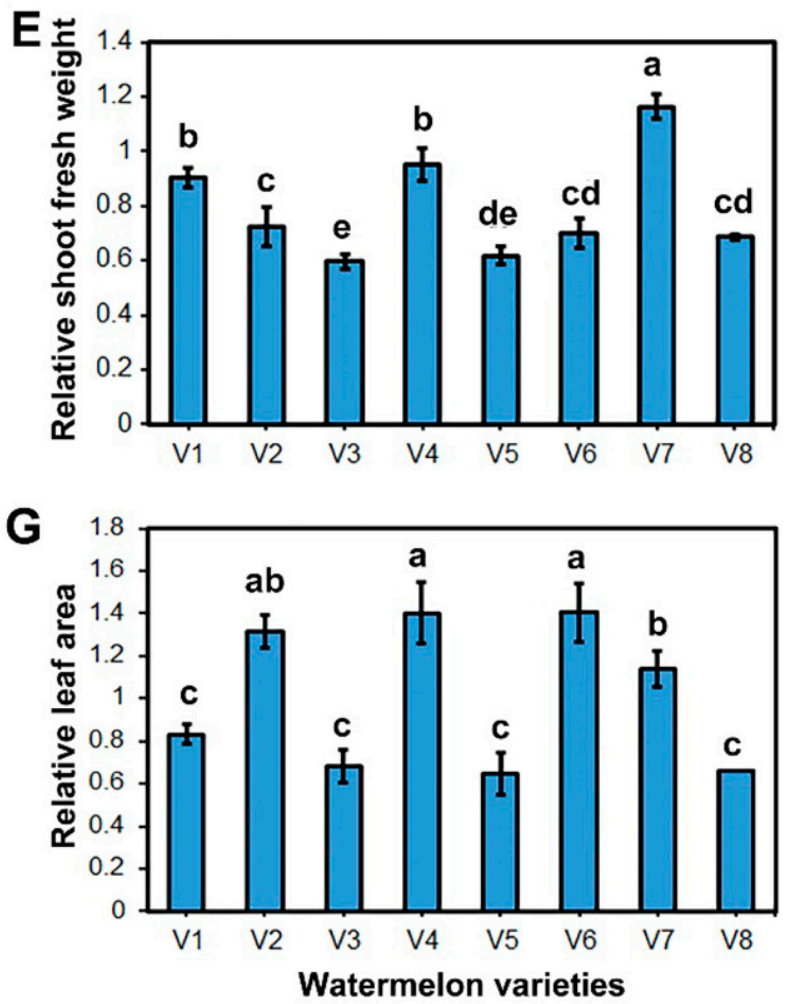

B

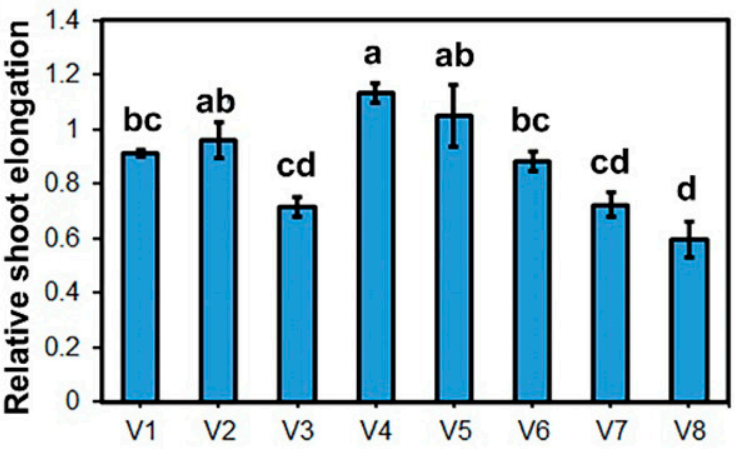

D

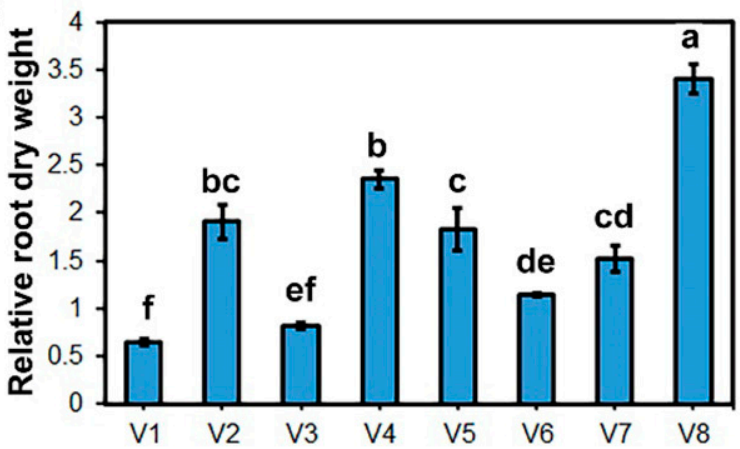

F

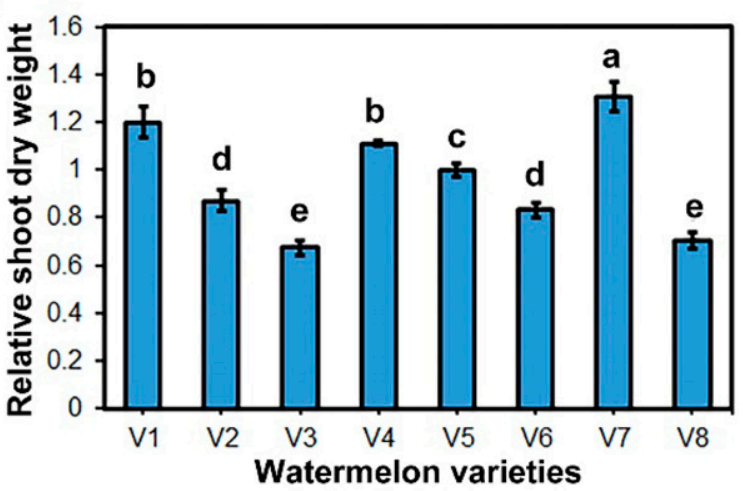

Fig. 3. The relative growth of the root and shoot of eight watermelon varieties after $14 \mathrm{~d}$ of exposure to $20 \mu \mathrm{M} \mathrm{Pb}$ in $\mathrm{Hoagland}$ 's nutrient solution.

(A) Relative root length. (B) Relative shoot height. (C) Relative root fresh weight. (D) Relative root dry weight. (E) Relative shoot fresh weight.

(F) Relative shoot dry weight. (G) Relative leaf area. Values given are mean \pm SD $(\mathrm{n}=3$ ). Values with different letters are significantly different $(P \leq 0.05)$ among treatments.

(Fig. 8D). CAT activity increased in all varieties in both leaves and roots. The greatest CAT activity in leaves and roots was recorded for V4 (724\%) and V7 (125\%) (Fig. 8E and F). APX activity increased slightly and decreased in Pb-tolerant and -sensitive watermelon varieties, respectively (Fig. 8G and $\mathrm{H}$ ).

Determination of $\mathrm{Pb}$ tolerance indicator parameters in watermelon. To determine $\mathrm{Pb}$ tolerance indicator parameters in watermelon varieties under $\mathrm{Pb}$ stress, $\mathrm{PCA}$ of different relative growth parameters was conducted to identify those that accounted for major component variability (Fig. 9A and $\mathrm{B})$. PCA revealed two components that accounted for $67.03 \%$ of the total variance. On one hand, PC1 accounted for $43.47 \%$ 
of the explained variance, which is shown in Eq. (3):

$$
\begin{aligned}
\mathrm{PC} 1= & 0.937 \mathrm{RRL}+0.896 \mathrm{RSDW} \\
& +0.792 \mathrm{RSFW}-0.341 \mathrm{RRDW} \\
& +0.311 \mathrm{RRFW}-0.062 \mathrm{RLA} \\
& +0.05 \mathrm{RSL}
\end{aligned}
$$

The second component (PC2) accounted for $23.56 \%$ of the total variance, which is shown in Eq. [4]:

$$
\begin{aligned}
\mathrm{PC} 2= & -0.92 \mathrm{RRL}+0.362 \mathrm{RSDW} \\
& +0.366 \mathrm{RSFW}+0.195 \mathrm{RRDW} \\
& +0.821 \mathrm{RRFW}+0.771 \mathrm{RLA} \\
& +0.767 \mathrm{RSL}
\end{aligned}
$$

This analysis identified RRL, RSDW, and RSFW (0.937, 0.896, and 0.792, respectively) as the main growth parameters contributing to the maximum principal component variation [as demonstrated in Eq. (3)]. Similarly, a significant correlation $(P<0.01)$ between RRL, RSFW, and RSDW was observed,

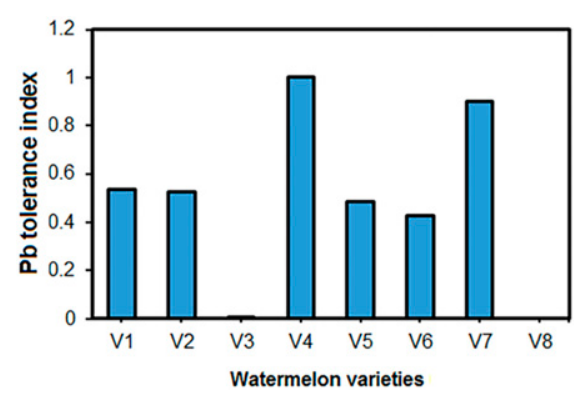

Fig. 4. $\mathrm{Pb}$ tolerance index of eight watermelon varieties after $14 \mathrm{~d}$ of exposure to $20 \mu \mathrm{M} \mathrm{Pb}$ in Hoagland's nutrient solution under greenhouse conditions.

A

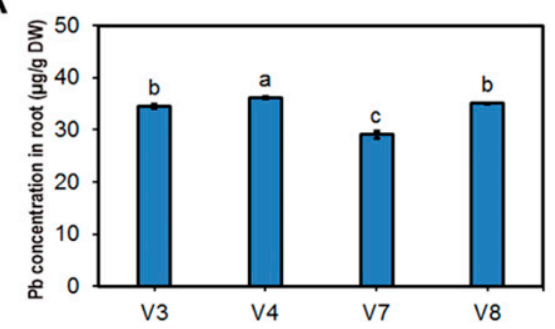

C

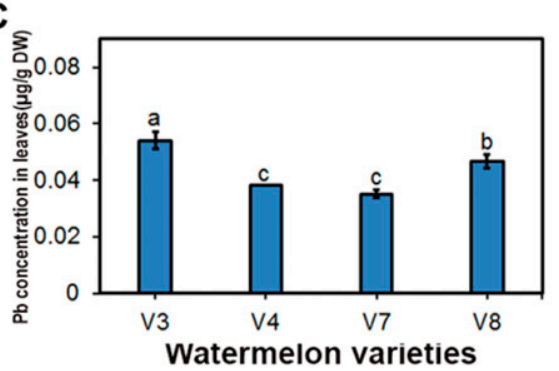

indicating that root growth affected shoot growth positively. These results reveal that better root growth under $\mathrm{Pb}$ stress is predictive of better shoot growth.

\section{Discussion}

$\mathrm{Pb}$ contamination in water, air, and soil is a global environmental issue. Plants exhibit various toxicity symptoms to $\mathrm{Pb}$ exposure, including stunted growth, a decrease in biomass production, and inhibition of root and shoot growth (Hattab et al., 2016; Kumar and Prasad, 2018). Watermelon is an important horticultural crop that is sensitive to $\mathrm{Pb}$ stress (Osei-Agyeman, 2017; Torki et al., 2018). Morphological screening of $\mathrm{Pb}$-tolerant watermelon varieties that translocate less $\mathrm{Pb}$ to aboveground parts will enhance our understanding of the $\mathrm{Pb}$ tolerance mechanism, which is as yet unknown.

After treatment with different $\mathrm{Pb}$ concentrations, the root dry weight of watermelon variety $\mathrm{ZJ}$ decreased with increasing $\mathrm{Pb}$ concentration in the hydroponic solution. However, the lower dose $(20 \mu \mathrm{M})$ of $\mathrm{Pb}$ increased root dry weight by $10.39 \%$ in comparison with control plants (Fig. 2E), which might be a result of the increased synthesis of polysaccharides in the cell walls after exposure to $\mathrm{Pb}$ (Sharma and Dubey, 2005). Similarly, dry weight of radish root (Ahmad et al., 2018), as well as corn seedlings (Małkowski et al., 2002), has also been enhanced by $\mathrm{Pb}$. In spinach, an increase in root dry weight was noted at $4.83 \mathrm{~mm} \mathrm{~Pb}$ (Khan et al., 2016). The reduction in root length was more pronounced at both lower and higher doses of $\mathrm{Pb}(20$ and $80 \mu \mathrm{M})$ in comparison with shoot height. Our results are in agreement with those observed for Medicago sativa (Hattab et al., 2016), Acalypha indica (Venkatachalam et al., 2017), and Thespesia populnea (Kabir et al., 2008). Because

B

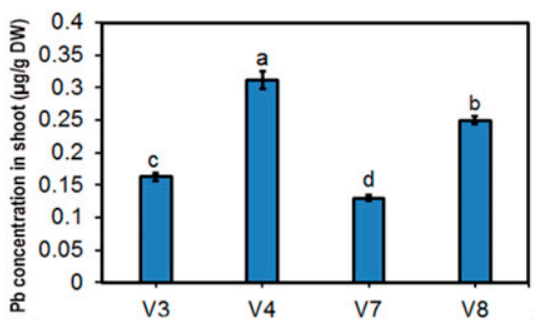

D

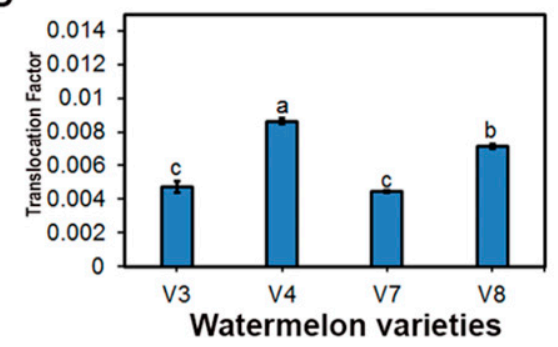

Fig. 5. $\mathrm{Pb}$ accumulation and translocation of six watermelon varieties exposed to $20 \mu \mathrm{M} \mathrm{Pb}$ for $14 \mathrm{~d}$. (A) $\mathrm{Pb}$ concentration in root. (B) $\mathrm{Pb}$ concentration in shoot. (C) Pb concentration in leaves. (D) Translocation factor of six watermelon varieties. Values given are mean $\pm \mathrm{SD}(\mathrm{n}=3)$. Values with different letters are significantly different $(P \leq 0.05)$ among varieties. DW, dry weight. plant response to $\mathrm{Pb}$ stress presents huge variations depending on genotype and tolerance mechanisms (Huang et al., 2017; Maodzeka et al., 2017), new statistical approaches are required to quantify $\mathrm{Pb}$ tolerance in watermelon via phenotype. In our study, $20 \mu \mathrm{M} \mathrm{Pb}$ was identified as the optimum dose to induce $\mathrm{Pb}$ toxicity, and MFA was used to classify $\mathrm{Pb}$ tolerance in watermelon. For heavy-metal tolerance quantification, MFA has been widely used in other plants such as wheat (Ci et al., 2011; Shi et al., 2015), sunflower (Ma et al., 2016), and tobacco (Maodzeka et al., 2017).

$\mathrm{Pb}$ accumulation was analyzed in the roots and shoots of different tolerant watermelon varieties, and diverse levels of $\mathrm{Pb}$ were found, which did not seem to correlate with $\mathrm{Pb}$ tolerance (Fig. 5). In all tested varieties, roots accumulated much more $\mathrm{Pb}$ than shoots. Similar results have been reported previously in lettuce (Liao et al., 2006), tobacco (Maodzeka et al., 2017), Salix integra (Wang et al., 2014), and Hibiscus cannabinus (Ho et al., 2008). This phenomenon might result from inhibited element upward transportation. Interestingly, significant differences were observed in shoot $\mathrm{Pb}$ accumulation of the two most Pb-tolerant varieties: V4 accumulated more than twice the $\mathrm{Pb}$ than that found in V7. Similarly, the most Pb-sensitive $\mathrm{V} 8$ accumulated more $\mathrm{Pb}$ than in another most $\mathrm{Pb}$-sensitive watermelon (Fig. 5B). However, the sensitive varieties accumulated significantly greater amount of $\mathrm{Pb}$ in leaves than the tolerant varieties (Fig. 5C). The translocation factor values of all watermelon were less than 1.0 , which is a key feature of non- $\mathrm{Pb}$ hyperaccumulator plant species (Fig. 5D), indicating that watermelon varieties are able to restrict much $\mathrm{Pb}$ in roots and greatly diminish upward movement to shoots, which might be a result of the binding of $\mathrm{Pb}$ with root cell wall ion exchange sites (Sun et al., 2020) and its extracellular precipitation in the form of $\mathrm{Pb}$ carbonates (Rucińska-Sobkowiak et al., 2013). Similarly, the strong binding ability of $\mathrm{Pb}$ with galacturonic and glucuronic acids in cell walls, and the restricting effect of the casparian strip are also responsible for its limited translocation (Wang et al., 2014).

Under $\mathrm{Pb}$ stress, MDA content increases in plant cells as a result of lipid peroxidation (Maodzeka et al., 2017). In our study, $\mathrm{Pb}$ stress induced more MDA generation in $\mathrm{Pb}$-sensitive varieties (Fig. 6A and $\mathrm{B}$ ). Comparable results have also been found in bamboo (Jiang et al., 2019), tobacco (Maodzeka et al., 2017), and Coronopus didymus (Sidhu et al., 2016). The increased MDA content in plants is a result of the formation of lipid peroxides from fatty acids. The greater MDA content is indicative of severe lipid peroxidation, which alters various physiobiochemical parameters as a result of oxidative stress (Sidhu et al., 2016).

Soluble protein and sugars (osmolytes) play important roles in plant defense against various abiotic stresses (Abdelkrim et al., 

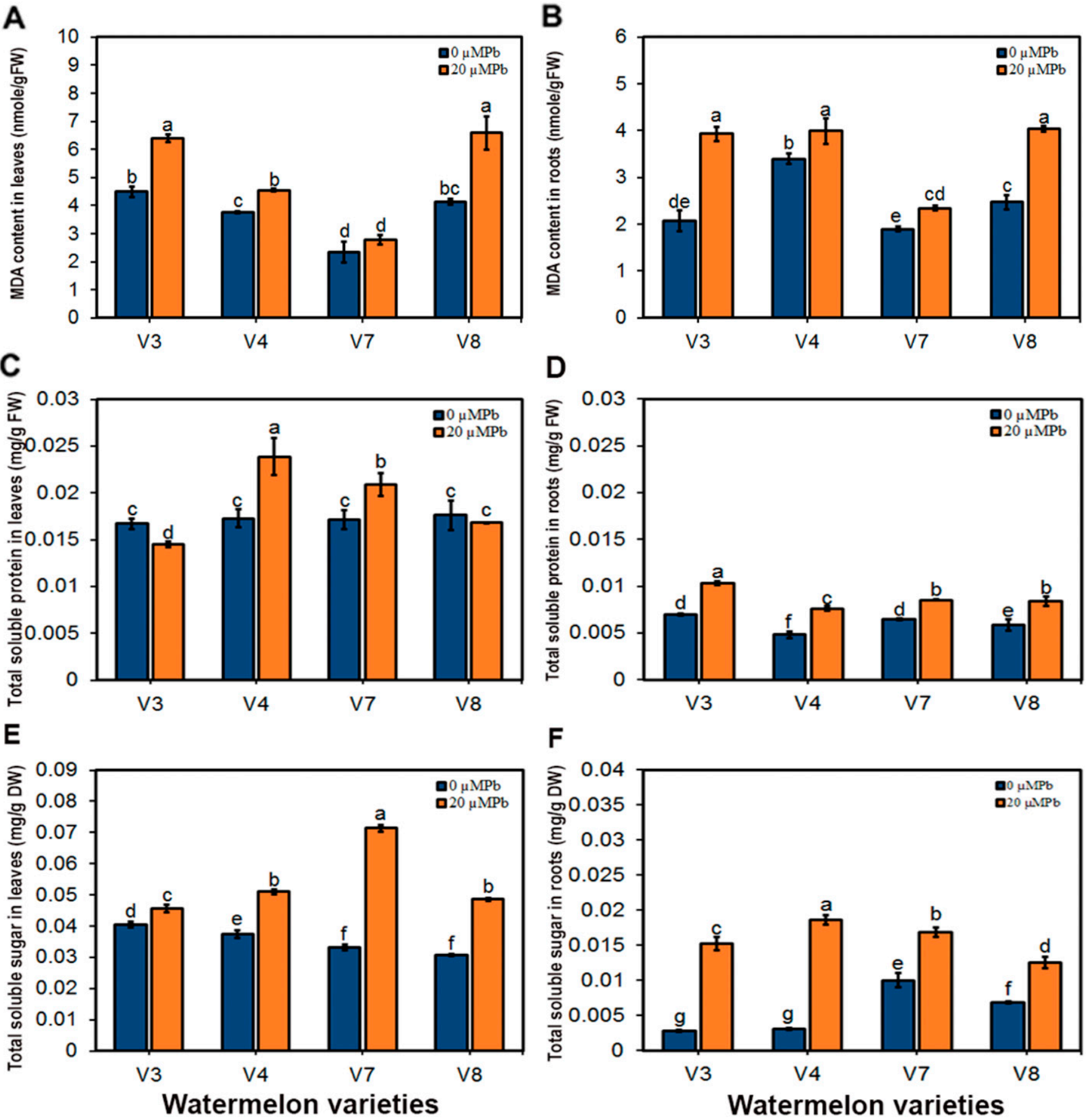

Fig. 6. Effect of $20 \mu \mathrm{M} \mathrm{Pb}$ on malondialdehyde (MDA), total soluble protein (TSP), and total soluble sugar (TSS) in the leaves and roots of four watermelon varieties. Vertical bars represent the mean $\pm \mathrm{SD}(\mathrm{n}=3)$. Values with different letters are significantly different $(P \leq 0.05)$ among varieties. DW, dry weight; FW, fresh weight.

2018; Jiang et al., 2019). The decrease in soluble sugars and protein pools under $\mathrm{Pb}$ stress may cause severe oxidative stress in plants (Abdelkrim et al., 2018; Jayasri and Suthindhiran, 2017; Piotrowska et al., 2009). The synthesis and accumulation of soluble protein and sugars in plants under heavy-metal stress is known to play various important roles, such as protection and stabilization of cell membranes and enzymes, maintenance of turgor, and scavenging of reactive oxygen species (ROS)
(Abdelkrim et al., 2018; Ali et al., 2014; Ashraf et al., 2017; Rodriguez et al., 2012). The accumulation of soluble protein in leaves was significantly induced in $\mathrm{Pb}$ tolerant varieties, but not in $\mathrm{Pb}$-sensitive watermelon (Fig. 6C and D). The synthesis of soluble sugars was stimulated in both leaves and roots of all varieties (Fig. 6E and $F$ ), implying that the enhanced amount of soluble protein and sugars may be a possible tolerance strategy against $\mathrm{Pb}$ stress in watermelon varieties.
In our study, $\mathrm{Pb}$ reversely affected chlorophyll and carotenoid content in watermelon. Interestingly, the opposite response pattern of each pigment was observed between two tolerant varieties as well as two sensitive genotypes (Fig. 7). A correlation between chlorophyll variation pattern and translocation factor was observed in all watermelon (Figs. 5 and 7). A reduction in chlorophyll and carotenoid contents as a consequence of $\mathrm{Pb}$ toxicity has been observed in tomato (Bali et al., 2019), spinach (Natasha et al., 2020), 


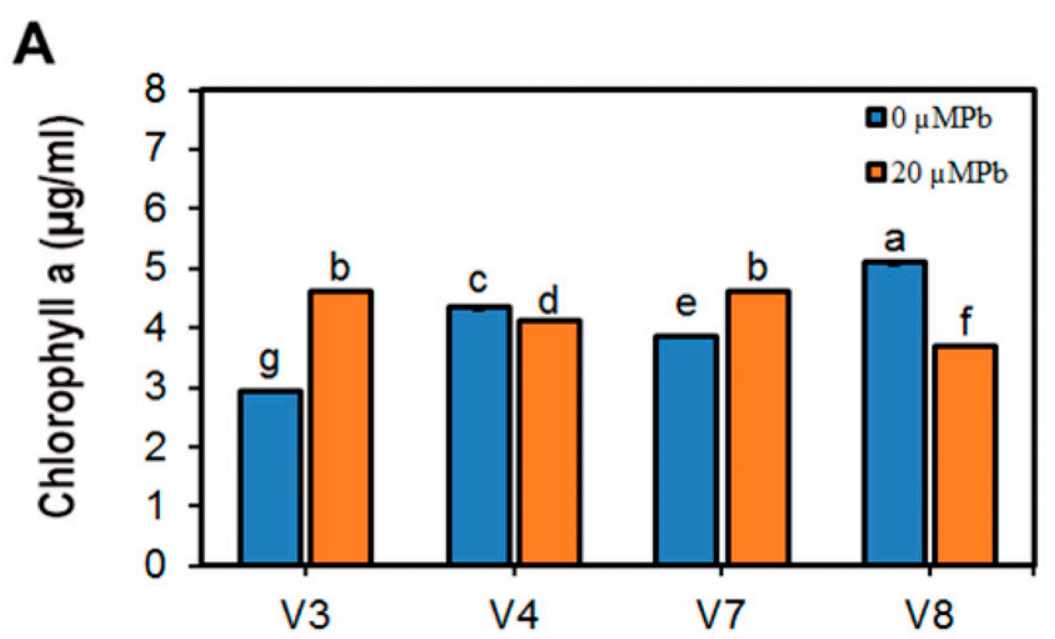

B
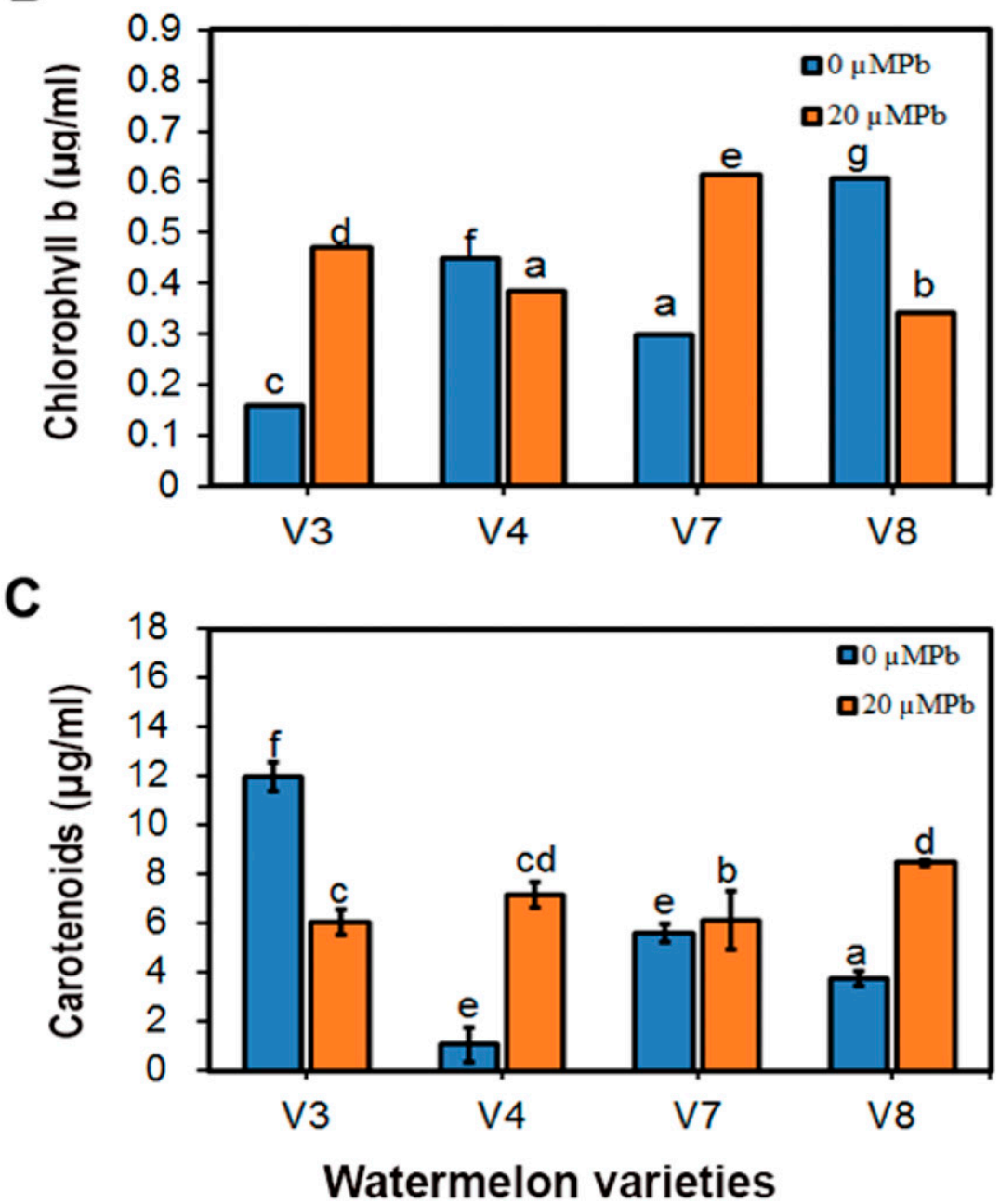

Fig. 7. Effect of $20 \mu \mathrm{M} \mathrm{Pb}$ on chlorophyll a, chlorophyll b, and carotenoids in the leaves of four watermelon varieties. Vertical bars represent the mean $\pm \mathrm{SD}(\mathrm{n}=3)$. Values with different letters are significantly different $(P \leq 0.05)$ among varieties.

tobacco (Maodzeka et al., 2017), Iris pseudacorus (Zhou et al., 2009), Brassica napus (Ferreyroa et al., 2017), and fodder turnip (Cenkci et al., 2010). Pb toxicity reduces chlorophyll content either by inhibiting its synthesis or enhancing degradation (Ferreyroa et al., 2017; Shakoor et al., 2014; Tian et al.,
2014). The inhibition of magnesium uptake and the decrease in the transport rate of iron to leaves by $\mathrm{Pb}$ may contribute to the high degradation rates of chlorophyll (Khan et al., 2016; Kumar and Prasad, 2018). Some studies have revealed the stimulatory effect of low doses of $\mathrm{Pb}$ on chlorophyll and carotenoid contents in Pogonatherum crinitum (Hou et al., 2018), Jatropha curcas L. cuttings (Saikachout et al., 2015), Atriplex varieties (Shu et al., 2012), Brassica napus (Ferreyroa et al., 2017), and Pseudochlorella pringsheimii (Ismaiel and Said, 2018).

Under $\mathrm{Pb}$ stress, ROS are produced in plant tissues, which cause oxidative stress. To lessen this stress, plants stimulate their antioxidative defense system to scavenge the ROS (Ashraf et al., 2017; Venkatachalam et al., 2017). SOD is a metalloenzyme involved in detoxifying the superoxide radical to $\mathrm{H}_{2} \mathrm{O}_{2}$ and dimer oxygen $\left(\mathrm{O}_{2}\right)$, and thus eliminates the ROS. POD also detoxifies free radicals that usually cause lipid peroxidation of membranes, thus protecting cell membranes from oxidative damage. CAT plays a key role in scavenging $\mathrm{H}_{2} \mathrm{O}_{2}$ in peroxisomes, and thus diminishes oxidative stress (Jayasri and Suthindhiran, 2017; Shakoor et al., 2014). APX, another enzyme present in chloroplasts, catalyzes the breakdown of $\mathrm{H}_{2} \mathrm{O}_{2}$ into water and $\mathrm{O}_{2}$ (Sidhu et al., 2016). In our study, significant and stronger enhancement of SOD, POD, CAT, and APX activities were observed in Pb-tolerant (V4 andV7) watermelon varieties, rather than in the more sensitive varieties (V3 and V8; Fig. 8), suggesting that the antioxidant system may contribute to $\mathrm{Pb}$ resistance in watermelon. Comparable results have also been reported in fragrant rice cultivars (Ashraf et al., 2017), tobacco (Maodzeka et al., 2017), and Peganum harmala (Mahdavian et al., 2016), in which the tolerant plants had elevated antioxidant enzyme activity compared with the sensitive plants. All these findings clearly suggest that the tolerant plants are better equipped to cope with $\mathrm{Pb}$ stress because of their greater antioxidant defense capability, in contrast to sensitive varieties.

Plant roots are the first response organ because of their direct contact with $\mathrm{Pb}$ in the environment. As a result of $\mathrm{Pb}$ toxicity, a sharp decrease in root growth occurs that might be the result of the inhibition of cell division in the root tip cells (Kumar and Prasad, 2018; Siddiqui, 2012). In a recent rice screening study, the only morphological difference between the $\mathrm{Pb}$-tolerant and -sensitive rice varieties and cultivars was found in the growth of roots (Yang et al., 2000). Indeed, many studies have reported that inhibition of root elongation should be one of the most prominent effects induced under $\mathrm{Pb}$ and other heavy-metal stress (Hattab et al., 2016; Wang et al., 2011). To see whether root length could be used as an indicator parameter for determining $\mathrm{Pb}$ tolerance and sensitivity among watermelon varieties, we performed PCA based on all relative growth parameters. According to our analysis, the relative growth parameters were graded in PC1 and PC2 based on their loaded eigenvalues from highest to lowest. The analysis identified the RRL, RSFW, and RSDW $(\mathrm{RRL}=0.937, \mathrm{RSDW}=0.896$, and $\mathrm{RSFW}=$ 0.792 eigenvalues, respectively) as the major growth parameters, which contributed to the maximum variation in principal components 

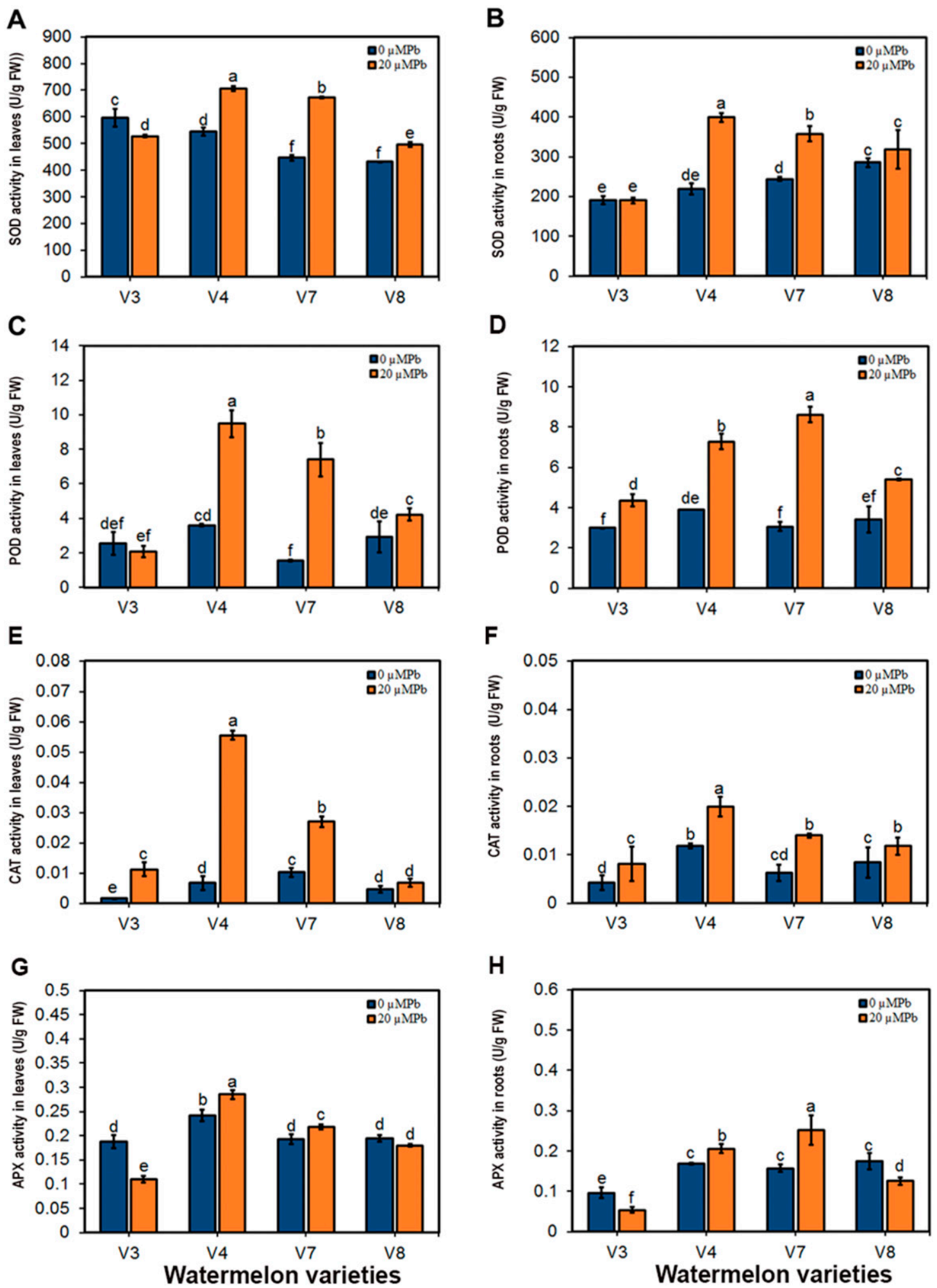

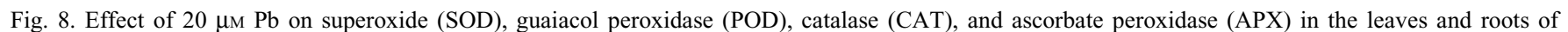
four watermelon varieties. Vertical bars represent the mean $\pm \mathrm{SD}(\mathrm{n}=3)$. Values with different letters are significantly different $(P \leq 0.05)$ among varieties. FW, fresh weight.

(Fig. 9A and B). Furthermore, RRL correlated significantly with RSFW and RSDW in both Pb-tolerant and -sensitive watermelon varieties. Taken together, these results suggest that RRL is a valid indicator parameter for the assessment of $\mathrm{Pb}$ tolerance and sensitivity at the seedling stage, predicting good development and high biomass production of the aboveground parts of watermelon. Similar results were reported in Medicago truncatula, in which relative root growth was used as an indicator parameter for the assessment of mercury tolerance at the seedling stage, and was confirmed, as plants with the greatest tolerance to this parameter showed good development of aerial parts (de la Torre et al., 2013). This could also be the main reason that root length is usually used as a measure for determining heavy-metal tolerance in plants. 


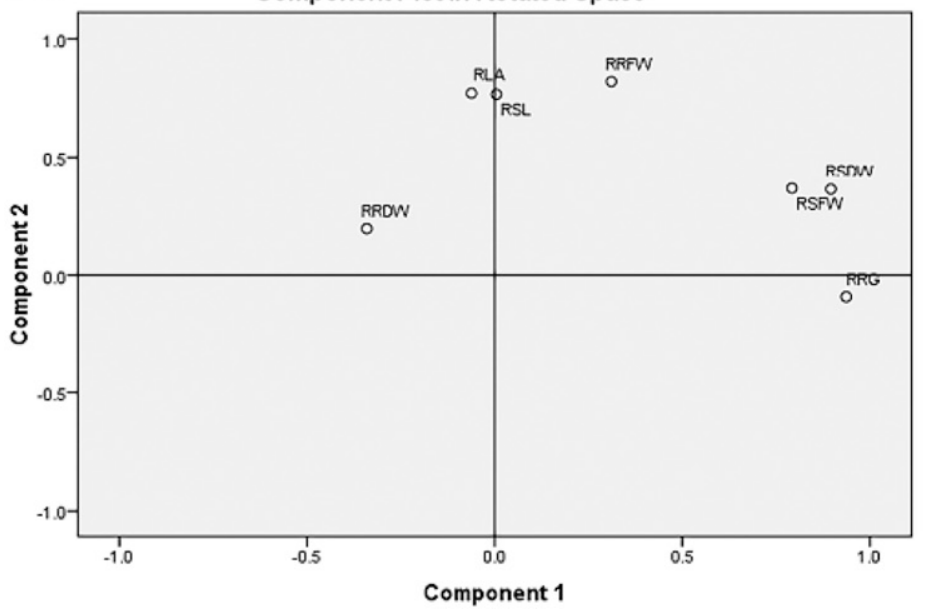

\begin{tabular}{|l|c|c|}
\hline \multirow{2}{*}{ Relative grooth } & \multicolumn{2}{|c|}{ Component } \\
\cline { 2 - 3 } prameters & 1 & 2 \\
\hline RRG & 0.937 & -0.092 \\
\hline RSDW & 0.896 & 0.362 \\
\hline RSFW & 0.792 & 0.366 \\
\hline RRDW & -0.341 & 0.195 \\
\hline RRFW & 0.311 & 0.821 \\
\hline RLA & -0.062 & 0.771 \\
\hline RSL & 0.005 & 0.767 \\
\hline
\end{tabular}

Fig. 9. The component plot in the rotated space of principal components 1 and 2 obtained from principal component analysis-determined Pb tolerance indicator parameters based on their relative growth parameters according to their Eigen values. RLA, relative leaf area; RRDW, relative root dry weight; RRFW, relative root fresh weight; RRG, relative root growth; RSDW, relative shoot dry weight; RSFW, relative shoot fresh weight; RSL, relative shoot length.

\section{Conclusions}

Our study concluded that 1) 2 weeks of exposure to $20 \mu \mathrm{M} \mathrm{Pb}$ (optimum condition) caused significant nonlethal toxicity in watermelon seedlings; 2) MFA identified and classified the most Pb-tolerant (V4 and V7) and the most $\mathrm{Pb}$-sensitive varieties (V3 and V8); 3 ) the tolerant varieties exhibited a differential $\mathrm{Pb}$ tolerance mechanism resulting from the significant difference in the translocation of $\mathrm{Pb}$; 4 ) in contrast to $\mathrm{Pb}$-sensitive varieties, $\mathrm{Pb}$ tolerant varieties maintained high antioxidant activity and low MDA content, as well as a greater level of TSP content in leaves; and 5) PCA identified RRL as an indicator of $\mathrm{Pb}$ tolerance in watermelon.

\section{Literature Cited}

Abdelkrim, S., S.H. Jebara, and M. Jebara. 2018 Antioxidant systems responses and the compatible solutes as contributing factors to lead accumulation and tolerance in Lathyrus sativus inoculated by plant growth promoting rhizobacteria. Ecotoxicol. Environ. Saf. 166:427-436.

Ahmad, I., M.J. Akhtar, S. Mehmood, K. Akhter, M. Tahir, M.F. Saeed, M.B. Hussain, and S. Hussain. 2018. Combined application of compost and Bacillus sp. CIK-512 ameliorated the lead toxicity in radish by regulating the homeostasis of antioxidants and lead. Ecotoxicol. Environ. Saf. 148:805-812.

Akıncı, I. and Ü. Çalışkan. 2010. Effect of lead on seed germination and tolerance levels in some summer vegetables. Ekoloji 19:164-172.

Alaboudi, K.A., B. Ahmed, and G. Brodie. 2018. Phytoremediation of $\mathrm{Pb}$ and $\mathrm{Cd}$ contaminated soils by using sunflower (Helianthus annuus) plant. Ann. Agr. Sci. 63:123-127.

Ali, B., T.M. Mwamba, R.A. Gill, C. Yang, S. Ali, M.K. Daud, Y. Wu, and W. Zhou. 2014. Improvement of element uptake and antioxidative defense in Brassica napus under lead stress by application of hydrogen sulfide. Plant Growth Regulat. 74:261-273.

Almasi, A., M. Mohammadi, S. Mosavi, and S. Eghbali. 2019. Phytoremediation potential of sewage sludge using native plants: Gossypium hirsutum L. and Solanum lycopersicum L. Intl. J. Environ. Sci. Technol. 16:6237-6246.

Arnon, D. and D. Hoagland. 1940. Crop production in artificial culture solutions and in soils with special reference to factors influencing yields and absorption of inorganic nutrients. Soil Sci. 50:463-485.

Ashraf, U., A.S. Kanu, Q. Deng, Z. Mo, S. Pan, H. Tian, and $\mathrm{X}$. Tang. 2017. Lead $(\mathrm{Pb})$ toxicity: Physio-biochemical mechanisms, grain yield, quality, and $\mathrm{Pb}$ distribution proportions in scented rice. Front. Plant Sci. 8:259. doi: 10.3389/ fpls.2017.00259.

Ashraf, U., M.H.-U.-R. Mahmood, S. Hussain, F. Abbas, S.A. Anjum, and X. Tang. 2020. Lead (Pb) distribution and accumulation in different plant parts and its associations with grain $\mathrm{Pb}$ contents in fragrant rice. Chemosphere 248:126003. doi: 10.1016/j.chemosphere.2020.126003.

Bali, S., V.L. Jamwal, S.K. Kohli, P. Kaur, R. Tejpal, V. Bhalla, P. Ohri, S.G. Gandhi, R. Bhardwaj, and A.A. Al-Huqail. 2019. Jasmonic acid application triggers detoxification of lead $(\mathrm{Pb})$ toxicity in tomato through the modifications of secondary metabolites and gene expression. Chemosphere 235:734-748

Bradford, M.M 1976. A rapid and sensitive method for the quantitation of microgram quantities of protein utilizing the principle of protein-dye binding. Anal. Biochem. 72:248-254.

Cândido, G.S., G.C. Martins, I.C. Vasques, F.R. Lima, P. Pereira, M.M. Engelhardt, R.H. Reis, and J.J. Marques. 2020. Toxic effects of lead in plants grown in Brazilian soils. Ecotoxicology 29:305-313.

Cenkci, S., I.H. Ciğerci, M. Yıldız, C. Özay, A Bozdağ, and H. Terzi. 2010. Lead contamination reduces chlorophyll biosynthesis and genomic template stability in Brassica rapa $\mathrm{L}$. Environ. Exp. Bot. 67:467-473.

Chen, M., L.-L. Zhang, J. Li, X.-J. He, and J.-C. Cai. 2015. Bioaccumulation and tolerance characteristics of a submerged plant (Ceratophyllum demersum L.) exposed to toxic metal lead. Ecotoxicol. Environ. Saf. 122:313-321.

Ci, D., D. Jiang, T. Dai, Q. Jing, and W. Cao. 2011. Variation in cadmium tolerance and accumulation and their relationship in wheat recombinant inbred lines at seedling stage. Biol. Trace Elem. Res. 142:807-818. de la Torre, V.S.G., T.C. de la Peña, M.M. Lucas, and J.J. Pueyo. 2013. Rapid screening of Medicago truncatula germplasm for mercury tolerance at the seedling stage. Environ. Exp. Bot. 91:90-96.

El-Moshaty, F.B., S. Pike, A. Novacky, and O. Sehgal. 1993. Lipid peroxidation and superoxide production in cowpea (Vigna unguiculata) leaves infected with tobacco ringspot virus or southern bean mosaic virus. Physiol. Mol. Plant Pathol. 43:109-119.

Ferreyroa, G.V., M.G. Lagorio, M.A. Trinelli, R.S. Lavado, and F.V. Molina. 2017. Lead effects on Brassica napus photosynthetic organs. Ecotoxicol. Environ. Saf. 140:123-130.

González-Valdez, E., A. Alarcón, R. Ferrera-Cerrato, H.R. Vega-Carrillo, M. Maldonado-Vega, and M.Á. Salas-Luévano. 2015. Seed germination and seedling growth of five plant species for assessing potential strategies to stabilizing or recovering metals from mine tailings. Water Air Soil Pollut. 227:24.

Hattab, S., S. Hattab, M.L. Flores-Casseres, H. Boussetta, P. Doumas, L.E. Hernandez, and M. Banni. 2016. Characterisation of lead-induced stress molecular biomarkers in Medicago sativa plants. Environ. Exp. Bot. 123:1-12.

He, S., Z. He, Q. Wu, L. Wang, and X. Zhang. 2015. Effects of GA3 on plant physiological properties, extraction, subcellular distribution and chemical forms of $\mathrm{Pb}$ in Lolium perenne. Intl. J. Phytoremediation 17:1153-1159.

Ho, W.M, L.H. Ang, and D.K. Lee. 2008. Assessment of $\mathrm{Pb}$ uptake, translocation and immobilization in kenaf (Hibiscus cannabinus L.) for phytoremediation of sand tailings. J. Environ. Sci. 20:1341-1347.

Hou, X., H. Han, L. Cai, A. Liu, X. Ma, C. Zhou, G. Wang, and F. Meng. 2018. Pb stress effects on leaf chlorophyll fluorescence, antioxidative enzyme activities, and organic acid contents of Pogonatherum crinitum seedlings. Flora 240:82-88

Huang, L., H. Zhang, Y. Song, Y. Yang, H. Chen, and M. Tang. 2017. Subcellular compartmentalization and chemical forms of lead participate in lead tolerance of Robinia pseudoacacia $\mathrm{L}$. with Funneliformis mosseae. Front. Plant Sci. 8:517.

Ismaiel, M.M. and A.A. Said. 2018. Tolerance of Pseudochlorella pringsheimii to $\mathrm{Cd}$ and $\mathrm{Pb}$ 
stress: role of antioxidants and biochemical contents in metal detoxification. Ecotoxicol. Environ. Saf. 164:704-712.

Jayasri, M. and K. Suthindhiran. 2017. Effect of zinc and lead on the physiological and biochemical properties of aquatic plant Lemna minor: Its potential role in phytoremediation. Appl. Water Sci. 7:1247-1253.

Jiang, D., Y.-Y. Wang, X.-W. Dong, and S.-C. Yan. 2018. Inducible defense responses in Populus alba berolinensis to $\mathrm{Pb}$ stress. S. Afr. J. Bot. 119:295-300.

Jiang, M., S. Liu, Y. Li, X. Li, Z. Luo, H. Song, and Q. Chen. 2019. EDTA-facilitated toxic tolerance, absorption and translocation and phytoremediation of lead by dwarf bamboos. Ecotoxicol. Environ. Saf. 170:502-512.

Kabir, M., M.Z. Iqbal, M. Shafiq, and Z. Farooqi. 2008. Reduction in germination and seedling growth of Thespesia populnea L., caused by lead and cadmium treatments. Pak. J. Bot. 40:2419-2426.

Khan, I., M. Iqbal, M.Y. Ashraf, M.A. Ashraf, and S. Ali. 2016. Organic chelants-mediated enhanced lead $(\mathrm{Pb})$ uptake and accumulation is associated with higher activity of enzymatic antioxidants in spinach (Spinacea oleracea L.). J. Hazard. Mater. 317:352-361.

Khan, M., M.D. Khan, A. Basharat, N. Muhammad, and Z. Shuijin. 2014. Differential physiological and ultrastructural responses of cottonseeds under $\mathrm{Pb}$ toxicity. Pol. J. Environ. Stud. 23:2063-2070.

Kong, S.-X., H. Su, Y.-T. Zhan, H.-K. Li, X.-S. Cui, and Y.-H. Guo. 2014. Effects of $\mathrm{Pb}^{2+}$ stress on seed germination \& seedling growth of Rabdosia rubescens. China J. Chinese Materia Medica 39:4216-4221.

Kumar, A. and M.N.V. Prasad. 2018. Plant-lead interactions: Transport, toxicity, tolerance, and detoxification mechanisms. Ecotoxicol. Environ. Saf. 166:401-418.

Liao, Y., S.C. Chien, M. Wang, Y. Shen, P. Hung, and B. Das. 2006. Effect of transpiration on $\mathrm{Pb}$ uptake by lettuce and on water soluble low molecular weight organic acids in rhizosphere. Chemosphere 65:343-351.

Lichtenthaler, H.K. and A.R. Wellburn. 1983. Determinations of total carotenoids and chlorophylls $\mathrm{a}$ and $\mathrm{b}$ of leaf extracts in different solvents. Portland Press Ltd, doi: 10.1042/ bst0110591.

Liu, Y., K. Chu, and J. Liu. 2020. Differences among ten wetland plant species in the tolerances of lead-polluted water. J. Environ. Protect. Sustain. Dev. 6:1-5.

Liu, J., X. Ma, M. Wang, and X. Sun. 2013. Genotypic differences among rice cultivars in lead accumulation and translocation and the relation with grain $\mathrm{Pb}$ levels. Ecotoxicol. Environ. Saf. 90:35-40.

Liu, J., X. Yang, G. Li, and C. He. 2009. Variations among rice genotypes and cultivars on root oxidation and $\mathrm{Pb}$ uptake. 3rd International Conference on Bioinformatics and Biomedical Engineering. IEEE. doi: 10.1109/ICBBE.2009.5163746.

Liu, N., L. Zhang, X. Meng, A. Nealam, J. Yang, and M. Zhang. 2014. Effect of nitrate/ammonium ratios on growth, root morphology and nutrient elements uptake of watermelon (Citrullus lanatus) seedlings. J. Plant Nutr. 37:1859-1872.

Ma, L., J. Sun, Z. Yang, and L. Wang. 2015. Heavy metal contamination of agricultural soils affected by mining activities around the Ganxi River in Chenzhou, southern China. Environ. Monit. Assess. 187:731.

Ma, T., W. Zeng, Q. Li, J. Wu, and J. Huang. 2016. Effects of water, salt and nitrogen stress on sunflower (Helianthus annuus L.) at differ- ent growth stages. J. Soil Sci. Plant Nutr. 16:1024-1037.

Mahdavian, K., S.M. Ghaderian, and H. Schat. 2016. $\mathrm{Pb}$ accumulation, $\mathrm{Pb}$ tolerance, antioxidants, thiols, and organic acids in metallicolous and non-metallicolous Peganum harmala L. under $\mathrm{Pb}$ exposure. Environ. Exp. Bot. 126:21-31.

Małkowski, E., A. Kita, W. Galas, W. Karcz, and J.M. Kuperberg. 2002. Lead distribution in corn seedlings (Zea mays L.) and its effect on growth and the concentrations of potassium and calcium. Plant Growth Regulat. 37:69-76.

Maodzeka, A., N. Hussain, L. Wei, G. Zvobgo, J.M. Mapodzeke, M.F. Adil, S. Jabeen, F. Wang, L. Jiang, and I.H. Shamsi. 2017. Elucidating the physiological and biochemical responses of different tobacco (Nicotiana tabacum) genotypes to lead toxicity. Environ. Toxicol. Chem. 36:175-181.

Morel, M., J. Crouzet, A. Gravot, P. Auroy, N. Leonhardt, A. Vavasseur, and P. Richaud. 2009. AtHMA3, a P1B-ATPase allowing Cd/ $\mathrm{Zn} / \mathrm{Co} / \mathrm{Pb}$ vacuolar storage in Arabidopsis. Plant Physiol. 149:894-904.

Moustafa-Farag, M., F. Bingsheng, K. Malangisha Guy, Z. Hu, J. Yang, and M. Zhang. 2016. Activated antioxidant enzymes-reduced malondialdehyde concentration, and improved mineral uptake-promoted watermelon seedlings growth under boron deficiency. J. Plant Nutr. 39:19892001.

Nas, F. and M. Ali. 2018. The effect of lead on plants in terms of growing and biochemical parameters: A review. OJ Ecology and Environmental Sciences 3:265-268.

Natasha, M. Shahid, A.B.U. Farooq, F. Rabbani, S. Khalid, and C. Dumat. 2020. Risk assessment and biophysiochemical responses of spinach to foliar application of lead oxide nanoparticles: A multivariate analysis. Chemosphere $245: 125605$

Osei-Agyeman, A.S. 2017. Analysis of watermelon from some selected farms in greater Accra region for nutritional and toxicological elements. PhD diss., University of Ghana. $<$ http://ugspace.ug.edu.gh/>.

Pidatala, V.R., K. Li, D. Sarkar, W. Ramakrishna, and R. Datta. 2016. Identification of biochemical pathways associated with lead tolerance and detoxification in Chrysopogon zizanioides L. Nash (Vetiver) by metabolic profiling. Environ. Sci. Technol. 50:2530-2537.

Piotrowska, A., A. Bajguz, B. GodlewskaŻyłkiewicz, R. Czerpak, and M. Kamińska. 2009. Jasmonic acid as modulator of lead toxicity in aquatic plant Wolffia arrhiza (Lemnaceae). Environ. Exp. Bot. 66:507-513.

Qiao, X., Z. Zheng, L. Zhang, J. Wang, G. Shi, and X. Xu. 2015. Lead tolerance mechanism in sterilized seedlings of Potamogeton crispus L.: Subcellular distribution, polyamines and proline. Chemosphere 120:179-187.

Radziemska, M., A. Bęś, Z.M. Gusiatin, G. Majewski, Z. Mazur, A. Bilgin, I. Jaskulska, and M. Brtnický. 2020. Immobilization of potentially toxic elements (PTE) by mineralbased amendments: Remediation of contaminated soils in post-industrial sites. Minerals 10:87.

Rao, G., U. Ashraf, S. Huang, S. Cheng, M. Abrar, Z. Mo, S. Pan, and X. Tang. 2018. Ultrasonic seed treatment improved physiological and yield traits of rice under lead toxicity. Environ. Sci. Pollut. Res. Intl. 25:33637-33644.

Rodriguez, E., C. Santos, R. Azevedo, J. MoutinhoPereira, C. Correia, and M.C. Dias. 2012. Chromium (VI) induces toxicity at different photosynthetic levels in pea. Plant Physiol. Biochem. 53:94-100.

Rucińska-Sobkowiak, R., G. Nowaczyk, M. Krzesłowska, I. Rabęda, and S. Jurga. 2013. Water status and water diffusion transport in lupine roots exposed to lead. Environ. Exp. Bot. 87:100-109.

Saikachout, S., A. Benmansoura, A. Ennajah, J. Leclerc, Z. Ouerghi, and N. Karray Bouraoui. 2015. Effects of Metal Toxicity on Growth and Pigment Contents of Annual Halophyte (A. hortensis and A. rosea). Intl. J. Environ. Res. 9. doi: 10.15666/aeer/0704_319332.

Seregin, I., L. Shpigun, and V. Ivanov. 2004. Distribution and toxic effects of cadmium and lead on maize roots. Russ. J. Plant Physiol. 51:525-533.

Shakoor, M.B., S. Ali, A. Hameed, M. Farid, S. Hussain, T. Yasmeen, U. Najeeb, S.A. Bharwana, and G.H. Abbasi. 2014. Citric acid improves lead $(\mathrm{Pb})$ phytoextraction in Brassica napus L. by mitigating $\mathrm{Pb}$-induced morphological and biochemical damages. Ecotoxicol. Environ. Saf. 109:38-47.

Sharma, P. and R.S. Dubey. 2005. Lead toxicity in plants. Braz. J. Plant Physiol. 17:35-52.

Sheng, Y., F. Luan, F. Zhang, and A.R. Davis. 2012. Genetic diversity within Chinese watermelon ecotypes compared with germplasm from other countries. J. Amer. Soc. Hort. Sci. 137:144-151.

Shi, G.L., S. Zhu, J.R. Meng, M. Qian, N. Yang, L.Q. Lou, and Q.S. Cai. 2015. Variation in arsenic accumulation and translocation among wheat cultivars: The relationship between arsenic accumulation, efflux by wheat roots and arsenate tolerance of wheat seedlings. J. Hazard. Mater. 289:190-196.

Shu, X., L. Yin, Q. Zhang, and W. Wang. 2012. Effect of $\mathrm{Pb}$ toxicity on leaf growth, antioxidant enzyme activities, and photosynthesis in cuttings and seedlings of Jatropha curcas L. Environ. Sci. Pollut. Res. Intl. 19:893-902.

Siddiqui, S. 2012. Lead induced genotoxicity in Vigna mungo var. HD-94. J. Saudi Soc. Agr. Sci. 11:107-112.

Sidhu, G.P.S., A.S. Bali, R. Bhardwaj, H.P. Singh, D.R. Batish, and R.K. Kohli. 2018. Bioaccumulation and physiological responses to lead $(\mathrm{Pb})$ in Chenopodium murale L. Ecotoxicol. Environ. Saf. doi: 10.1016/j.ecoenv.2017.12.068.

Sidhu, G.P.S., H.P. Singh, D.R. Batish, and R.K. Kohli. 2016. Effect of lead on oxidative status, antioxidative response and metal accumulation in Coronopus didymus. Plant Physiol. Biochem. 105:290-296.

Sun, H., M. Meng, L. Wu, X. Zheng, Z. Zhu, and S. Dai. 2020. Function and mechanism of polysaccharide on enhancing tolerance of Trichoderma asperellum under $\mathrm{Pb}^{2+}$ stress. Intl. J. Biol. Macromol. doi: 10.1016/j.ijbiomac.2020.02.207.

Sun, J. and L. Luo. 2018. Subcellular distribution and chemical forms of $\mathrm{Pb}$ in corn: Strategies underlying tolerance in $\mathrm{Pb}$ stress. J. Agr. Food Chem. 66:6675-6682.

Tian, T., B. Ali, Y. Qin, Z. Malik, R.A. Gill, S. Ali, and W. Zhou. 2014. Alleviation of lead toxicity by 5 -aminolevulinic acid is related to elevated growth, photosynthesis, and suppressed ultrastructural damages in oilseed rape. Biomed. Res. Int. 2014. doi: 10.1155/2014/530642.

Torki, Z., M. Mehrasebi, F. Nazari, K. Kamali, and M. Hosseini. 2018. Concentration and exposure assessments of cadmium and lead in pumpkin, sunflower, watermelon, and jabooni seeds collected in Iran. Fruits doi: 10.17660/th2018/73.4.5.

Venkatachalam, P., N. Jayalakshmi, N. Geetha, S.V. Sahi, N.C. Sharma, E.R. Rene, S.K Sarkar, and P.J.C. Favas. 2017. Accumulation efficiency, genotoxicity and antioxidant defense mechanisms in medicinal plant Acalypha 
indica L. under lead stress. Chemosphere 171:544-553.

Wang, S., X. Shi, H. Sun, Y. Chen, H. Pan, X. Yang, and T. Rafiq. 2014. Variations in metal tolerance and accumulation in three hydroponically cultivated varieties of Salix integra treated with lead. PLoS One doi: 10.1371/journal.pone. 0108568.

Wang, X., Y. Song, Y. Ma, R. Zhuo, and L. Jin. 2011. Screening of $\mathrm{Cd}$ tolerant genotypes and isolation of metallothionein genes in alfalfa (Medicago sativa L.). Environ. Pollut. 159:3627-3633.

Wei, B. and L. Yang. 2010. A review of heavy metal contaminations in urban soils, urban road dusts and agricultural soils from China. Microchem. J. 94:99-107.

Yang, Y.-Y., J.-Y. Jung, W.-Y. Song, H.-S. Suh, and Y. Lee. 2000. Identification of rice va- rieties with high tolerance or sensitivity to lead and characterization of the mechanism of tolerance. Plant Physiol. 124:10191026.

Yemm, E. and A. Willis. 1954. The estimation of carbohydrates in plant extracts by anthrone. Biochem. J. 57:508.

Zhivotovsky, O.P., J.A. Kuzovkina, C.P. Schulthess, T. Morris, D. Pettinelli, and M. Ge. 2010. Hydroponic screening of willows (Salix L.) for lead tolerance and accumulation. Intl. J. Phytoremediation 13:75-94.

Zhong, B., J. Chen, M. Shafi, J. Guo, Y. Wang, J. Wu, Z. Ye, L. He, and D. Liu. 2017. Effect of lead (Pb) on antioxidation system and accumulation ability of Moso bamboo (Phyllostachys pubescens). Ecotoxicol. Environ. Saf. 138:71-77.

Zhou, J., Z. Zhang, Y. Zhang, Y. Wei, and Z. Jiang. 2018. Effects of lead stress on the growth, physiology, and cellular structure of privet seedlings. PLoS One doi: 10.1371/journal. pone. 0191139

Zhou, R., W. Liu, and Q. Zhou. 2015. Method for remediating soil with single or combined contamination of $\mathrm{Cd}$ and $\mathrm{Pb}$ by hyperaccumulator Emilia sonchifolia L. US patent application 14/341822. <http://www.freepatentsonline.com/ y2015/0101247.htm>.

Zhou, Y., Y. Wang, M. Li, Z. Gao, Q. Hu, and S. Gao. 2014. Anatomical and biochemical characteristics of Achnatherum splendens (Trin.) Nevski seedlings stressed on $\mathrm{Pb}^{2+}$. Appl. Biochem. Biotechnol. 172:3176-3193.

Zhou, Y.-Q., S.-Z. Huang, S.-L. Yu, J.-G. Gu, J.-Z. Zhao, Y.-L. Han, and J.-J. Fu. 2009. The physiological response and sub-cellular localization of lead and cadmium in Iris pseudacorus L. Ecotoxicology 19:69. 
Supplemental Table 1. The composition of the Hoagland nutrient solution (full/half strength and modified).

\begin{tabular}{|c|c|c|c|c|}
\hline \multirow[b]{2}{*}{ S. no. } & \multirow[b]{2}{*}{ Chemical name } & \multicolumn{3}{|c|}{ Hoagland's nutrient solution (chemical concn, mg/L) } \\
\hline & & Full strength & Half strength & Modified \\
\hline 2 & $\mathrm{Ca}\left(\mathrm{NO}_{3}\right)_{2} 4 \mathrm{H}_{2} \mathrm{O}$ & 253 & 126.5 & 126.5 \\
\hline 5 & $\mathrm{Na}_{2} \mathrm{Fe}$-EDTA & 30 & 15 & 15 \\
\hline 6 & $\mathrm{H}_{3} \mathrm{BO}_{3}$ & 1.43 & 0.715 & 0.715 \\
\hline 7 & $\mathrm{MnSO}_{4} \cdot \mathrm{H}_{2} \mathrm{O}$ & 1.065 & 0.5325 & 0.5325 \\
\hline 10 & $\left(\mathrm{NH}_{4}\right)_{6} \mathrm{Mo}_{7} \mathrm{O}_{24} \cdot 4 \mathrm{H}_{2} \mathrm{O}$ & 0.01 & 0.005 & 0.005 \\
\hline
\end{tabular}

